\title{
Capacidade estatal: definições, dimensões e mensuração
}

\author{
Rafael Barbosa de Aguiarr (1) \\ Luciana Leite Lima ${ }^{\mathrm{I}}$ (D)
}

\section{Introdução'}

O debate sobre as capacidades estatais está fortemente ligado ao da promoção do desenvolvimento. Historicamente, entre as décadas de 1930 e 1970 (sobretudo após as duas Guerras Mundiais), cabia ao Estado a criação de alternativas para superação do atraso econômico e social por meio da condução de projetos de industrializaçáo, especialmente nos países subdesenvolvidos. A intervenção estatal era vista como um meio capaz de gerar desenvolvimento: acelerar a industrialização, modernizar a agricultura e prover a infraestrutura necessária à urbanização (Evans, 1993; Gomide, 2016).

Todavia, a mudança na conjuntura internacional no final dos anos 1970 e no início da década de 1980 (choques do petróleo e crise de liquidez global) levou ao questionamento do papel do Estado no desenvolvimento econômico. Tal postura encontrou fundamentação na teoria da escolha pública, que direcionou a atenção à investigação das falhas de governo, explorando as externalidades negativas da intervenção estatal. Ideias provenientes desse programa de investigação, modeladas para a arena política, deram forma ao neoliberalismo. Todo esse contexto alcançou as abordagens da gestão governamental, fomentando a desconfiança em relação à capacidade do Estado de alcançar objetivos socialmente relevantes, já que estaria capturado pelos diversos grupos que disputam os recursos que concentra (Evans, 1995).

No fim dos anos 1990, o desemprego, a instabilidade financeira e o alto grau de pobreza encontrados em países que adotaram as medidas do Consenso de Washington levaram à perda de legitimidade dessa agenda. A partir daí, nenhuma posição sobre qual deve ser o papel do Estado para o desenvolvimento adquiriu hegemonia teórica ou política - sobretudo após a crise financeira mundial de 2008-2009 (Gomide, 2016).

De acordo com Souza (2017), em virtude da contribuição de cientistas sociais como Peter Evans, Theda Skocpol e Michael Mann, o debate sobre modernização e subdesenvolvimento tomou novo rumo, incorporando o entendimento de que os atributos

'Programa de Pós-Graduação em Políticas Públicas, Universidade Federal do Rio Grande do Sul - Porto Alegre (RS), Brasil. E-mails: rafaelba@yahoo.com.br; lucianaleitelima@gmail.com

${ }^{1}$ Agradecemos os comentários e sugestóes dos pareceristas anônimos da Revista Brasileira de Informação Bibliográfica em Ciências Sociais (BIB). Qualquer equívoco ou omissáo é responsabilidade exclusiva dos autores.

Recebido em: 21/02/2019. Aprovado em: 20/04/2019. 
do Estado são necessários, mas insuficientes para a produção de bens e serviços públicos. Além disso, seria necessária a criação de mecanismos capazes de viabilizar o poder estatal e fazê-lo atingir diversos grupos sociais e territoriais. A partir de tais contribuiçóes, a noção de capacidade estatal passou a figurar na produçáo e no debate acadêmico e gerencial.

Este trabalho objetivou sistematizar essa literatura, partindo da pesquisa realizada por Cingolani (2013), visto que é um estudo recente de fôlego, que revisou a literatura internacional. Contudo, nossa contribuição será trabalhar esses dados englobando a literatura nacional, dando ênfase às definiçóes, às dimensões da capacidade estatal $\mathrm{e}$ às formas de mensurá-las.

\section{Da variedade conceitual}

O conceito de capacidades estatais foi desenvolvido em estudos de sociologia e economia política que se debruçaram sobre a análise do papel do Estado na promoção do desenvolvimento econômico. Atualmente, o conceito vem adquirindo centralidade nas análises sobre a efetividade do Estado no sentido da "boa governança" (Cingolani, 2013; Gomide, 2016).

Os trabalhos de Charles Tilly (1975), Theda Skocpol (1979), Evans, Rueschemeyer e Skocpol (1985) e Peter Evans (1995) forneceram as ideias desenvolvidas em Cingolani (2013), Cingolani, Thomsson e Crombrugge (2013), Evans e Rauch (1999) e Jessop (2001), além de terem inspirado, no Brasil, Gomide (2016), Souza $(2016,2017)$ e Bichir (2016), entre outros.

De acordo com Jessop (2001) apud Cingolani (2013), na ciência política, a re- levância do Estado foi reinstalada em duas ondas: nos anos 1960, pelas teorias marxistas sobre o Estado capitalista; e, nos anos 1970 e 1980 , por meio do movimento institucional estadista. A primeira onda ocorreu na Europa e foi motivada pela necessidade da reavaliaçẫo da visão marxista do Estado, considerando os efeitos redistributivos da economia do bem-estar que emergia (Esping-Andersen, 1991). Esta sugeria que o Estado poderia não ser sempre e diretamente um órgão de classe, mas, contextualmente, poderia se autonomizar em relaçáo à burguesia, embora mantida a subordinação estrutural.

A segunda onda teve início nos Estados Unidos e se caracterizou pelo afastamento em relação às perspectivas marxistas e behavioristas nos estudos sobre a ação governamental (Cingolani, 2013). Mudou o foco: da sociedade para o Estado. Com base na tradição weberiana, duas principais características dos Estados modernos receberam atenção: "A importância da monopolização do poder coercitivo pela administração central e a formação de quadros de serviço público profissionais, permanentes e insulados"2 (Cingolani, 2013, p. 4).

Nessa linha, os autores clássicos que abordaram a importância da monopolização do poder coercitivo são Tilly (1975) e Midgal (1988). Tilly (1975) estudou o papel da guerra na formaçáo dos Estados na Europa Ocidental. Para o autor, o nível de intervençấo do Estado é determinado pela capacidade de arrecadar impostos, isto é, a capacidade de "construir um aparato que efetivamente extraia os recursos necessários da população e que controle seus esforços para resistir à extração desses recursos" (Tilly, 1975, p. 40).

2 Todas as traduçóes foram feitas pelos autores. 
Já Midgal (1988) demonstrou como as capacidades estatais configuravam-se em países em desenvolvimento: por que alguns são capazes de estabelecer regras comportamentais mais efetivas para a sociedade e outros não? Ele sustentou que sociedades fortes afetam a capacidade do Estado de atingir seus objetivos, já que conseguiriam resistir à intervenção. Para tanto, o autor define como capacidade estatal "a habilidade dos líderes do Estado em usar suas agências para induzir as pessoas a fazerem o que eles querem que elas façam" (Midgal, 1988, prólogo). Em contraste com a visão estadocêntrica, $o$ autor afirma que a chave para explicar a capacidade estatal é a distribuição do controle social entre diversas organizaçóes, incluindo o Estado (Cingolani, 2013; Cingolani; Thomsson; de Crombrugghe, 2013).

Entre os estudos envolvendo tanto a importância da monopolização do poder coercitivo quanto a formaçáo de quadros de serviço público profissionais, sobressaem Skocpol (1979), Evans, Rueschemeyer e Skocpol (1985), Evans (1995) e Weiss (1998).

Skocpol (1979) analisou a interação entre o aparato estatal, as elites e os burocratas, demonstrando que a natureza dessa relação pode determinar a autonomia do Estado, especialmente em suas capacidades administrativa, coercitiva e extrativa. A autora mostrou que a falta de controle do aparelho estatal pela classe aristocrática é fundamental para criar oportunidades de surgimento de revoluçóes sociais, desencadeando mudanças estruturais fundamentais. Por sua vez, Evans, Rueschemeyer e Skocpol (1985) evidenciaram como a autonomia do Estado opera no processo de definição de diferentes metas políticas. Nesse sentido, Skocpol (1985, p. 9) definiu a capacidade estatal como a "habilidade para implementar objetivos oficiais, especialmente sobre a atual ou potencial oposição de grupos sociais poderosos ou diante de circunstâncias socioeconômicas recalcitrantes".

Já Evans (1995) investigou as características que permitiriam aos Estados agir de forma a promover o crescimento econômico. $\mathrm{O}$ autor argumenta que a gama de açóes que um governo pode tomar depende dos diferentes tipos de estruturas estatais existentes, bem como do tipo de relaçáo que os Estados estabelecem com os grupos sociais. Assim, as intervençóes mais efetivas seriam resultado da combinação entre uma burocracia competente e coerente, por isso autônoma, e parcerias com os grupos sociais envolvidos. Variações nestes dois elementos (autonomia e parceria) criariam diferentes capacidades estatais.

Weiss (1998), em consonância com Evans (1995), estudou a habilidade transformativa do Estado no contexto da globalização, referindo-se a esta como "capacidade do Estado de se adaptar aos choques e pressóes externas, gerando meios sempre novos de governar o processo de mudança industrial" (Weiss, 1998, p. 4). A autora defende o papel do Estado na coordenação de mudanças industriais para enfrentar a competição internacional. Enfatiza também a persistência da centralidade do Estado na economia, desafiando os pontos de vista da opinião pública sobre o desaparecimento do Estado em um mundo crescentemente globalizado (Cingolani, 2013; Cingolani; Thomsson; de Crombrugghe, 2013).

Enfim, vimos que no debate sobre capacidades estatais existem diversas definiçôes para o conceito, algumas complexas e outras mais simples, entretanto, puderam-se observar algumas congruências. Uma delas diz respeito à centralidade do Estado de exer- 
cer suas funçôes de forma profissionalizada e insulada de interesses dos grupos sociais. Os primeiros trabalhos do campo privilegiaram a capacidade fiscal, coercitiva e de penetração no território, tendo em vista a extração de recursos financeiros da população e a minimização das resistências correspondentes. Outros estudos prolíficos passaram a incorporar a sociedade náo mais como agente passivo, mas como ator de relevância.

Sobre essa pluralidade de definiçôes e enfoques, resta ainda averiguar sua adequabilidade a diferentes contextos. Tal indagação encaminhou nosso olhar para trabalhados desenvolvidos no Brasil, conforme segue.

\section{Estudos recentes sobre capacidade estatal no Brasil}

A vasta literatura internacional sobre capacidade estatal inspirou uma série de estudos no Brasil. Neste tópico, discutiremos alguns trabalhos nacionais recentes, sistematizados segundo as áreas de políticas enfocadas: desenvolvimento, burocracia, inovação, industrial, infraestrutura energética, ambiental, trabalho e seguridade social, social, comércio exterior, cooperação internacional e internacionalização econômica. Nesse caminho, ressaltaremos o conceito empregado na análise, bem como a dimensão enfatizada e a relação de causalidade estabelecida. Vale ressaltar que esse levantamento não foi exaustivo, focamos nos trabalhos mais representativos de cada campo, considerando o espaço disponível e o objetivo deste artigo.

Análises de políticas de desenvolvimento foram realizadas por Gaitán e Boschi (2016), Gomes (2016), Gomide e Pires (2012) e Nunes (2018). Gaitán e Boschi (2016) investigaram o papel das coalizóes de governo na formulação de um projeto de desenvolvimento socioeconômico, relacionando a existência de coalizóes de apoio à sustentabilidade temporal de políticas públicas, de modo que uma agenda nacional de desenvolvimento pudesse prosperar e se manter. Gomes (2016), por sua vez, analisou como instituições de representação extraparlamentares poderiam ampliar as capacidades estatais de interlocuçáo entre o Estado e a sociedade civil, possibilitando a formulação de novas políticas de desenvolvimento.

Ainda nessa área de política, Gomide e Pires (2012) categorizaram o entrelaçamento entre as dimensôes democrática e burocrática a partir da combinaçáa de dois eixos: o técnico-administrativo (associado à competência da burocracia estatal em traçar, implementar e coordenar estratégias em diferentes níveis de governo) e o político (associado à habilidade dos atores do Estado de expandir os canais de interlocução com a sociedade civil e atores do sistema político-representativo nos processos de políticas públicas). Seguindo essa proposta, Nunes (2018) estudou se as capacidades burocráticas e políticas existentes, entre 2003 e 2010, foram suficientes para a execução da estratégia de desenvolvimento dos dois mandatos do governo Lula. $\mathrm{O}$ autor constatou que o Estado náo tinha as capacidades necessárias para implementar uma estratégia nos moldes pretendidos; consequentemente, o projeto encontrou obstáculos difíceis de contornar. Como limitações o autor apontou a ausência de uma burocracia suficientemente autônoma e competente, bem como estrategicamente inserida na sociedade, para tomar as principais decisões acerca da política econômica, o que conferiria apoio político tanto ao processo decisório quanto ao de construçáo institucional.

Nota-se que a temática da relação entre o Estado e a sociedade é recorrente nos estu- 
dos sobre políticas de desenvolvimento. Segundo Evans (1995), isso se deve ao fato de que o desenvolvimento é um objetivo compartilhado pelos atores e cuja consecução depende de ação concertada. Desse modo, é interessante verificar como essa questáo se manifesta nas políticas e nas análises.

Pesquisando o tema da qualidade da burocracia, Souza (2016) examinou a profissionalização, a qualificação e a forma de recrutamento dos quadros burocráticos de agências governamentais no Brasil e na Argentina, com o objetivo de investigar a capacidade de implementaçáo de políticas. A autora identificou que, nos dois países, a capacidade burocrática não era distribuída uniformemente entre as agências governamentais, o que poderia ser explicado pela dependência da trajetória (path dependence), principalmente quanto à agenda de redemocratização e aos diferentes momentos das reformas constitucionais e institucionais. Em outro trabalho, analisando o processo de modernização do Estado brasileiro, Souza (2017) associou o conceito de capacidade estatal à profissionalização da burocracia federal. Para a autora, a redemocratizaçáo alicerçou o padráo de recrutamento por concursos públicos, consolidando características weberianas na burocracia, o que teria gerado maior propensão para atuar no controle das regras, dos procedimentos e do âmbito fiscal, assegurando a eficácia das políticas públicas. Ela concluiu que, se por um lado, a capacidade burocrática do Executivo federal estaria promovendo a implementação de políticas preferenciais, por outro, sua distribuição seria desigual entre setores de políticas.

Na mesma linha, Marenco, Strohschoen e Joner (2017) utilizaram a capacidade burocrática, entendida enquanto a combinaçáo de autonomia profissional e capacidade téc- nica, para identificar discrepâncias entre os municípios brasileiros (no que diz respeito a indicadores desses recursos) e o quanto os recursos influenciam a habilidade de tributar dos municípios brasileiros. Os resultados mostraram que administraçóes municipais com serviço público mais profissionalizado têm maiores chances de incrementar suas arrecadaçôes do imposto patrimonial. De forma similar, Grin et al. (2018) testaram a hipótese de que quanto mais as localidades dispusessem de capacidades estatais, mais qualificada seria a sua gestão fiscal. Os autores avaliaram a estrutura organizacional, as habilidades para formular e gerir políticas, bem como a qualificação dos recursos humanos e do planejamento municipal. Além disso, analisaram o poder para legislar sobre regulaçóes que afetam o comportamento dos atores econômicos e influenciam a performance fiscal local. E, por fim, examinaram como o governo municipal estabelece canais de interlocução para lidar com demandas sociais por meio de conselhos de políticas públicas e consórcios intermunicipais.

O tema da qualidade da burocracia é um dos mais pesquisados na literatura internacional sobre capacidades estatais (Bäck e Hadenius, 2008; Evans e Rauch, 1999; Geddes, 1994; Hendrix, 2010). No Brasil, como vimos, a aproximaçáo com as capacidades burocráticas/administrativas é comumente realizada por meio da utilização das características weberianas, a exemplo da qualificação da burocracia e do recrutamento meritocrático.

Passemos agora às políticas de inovação. Castro (2016) analisou a capacidade estatal de formular e implementar estratégias e de contornar e evitar armadilhas em países de renda média, destacando as dimensóes políticas (tomada de decisão e direção), buro- 
cráticas (formulação e implementação de políticas públicas), relacionais (busca por consensos) e financeiras. Sob outra perspectiva, Jaguaribe (2016) enfocou a capacidade de formular, coordenar e executar objetivos de política tecnológica, examinando a evoluçấo da iniciativa chinesa a partir de seus objetivos, governança e visão de futuro. Segundo ele, tais elementos, ao longo de um processo de reforma, propiciaram transformaçôes na abrangência e na complexidade da política, de modo a formar um paradigma de política técnico-industrial.

Para políticas de inovação, a recorrência que surge nos estudos de Castro (2016) e Jaguaribe (2016) é a utilização das capacidades burocráticas e relacionais. Desse modo, enfatizam-se os processos de formulação e implementação por meio da conexão com grupos diversos da sociedade, com vistas à mobilização de recursos políticos necessários ao funcionamento da política (Gomide, 2016).

Em relação à política industrial, Delgado (2016) investigou a capacidade de coordenação na China, na Índia e no Brasil. Para o autor, a especificidade dessa área exige a atuaçâo de organismos permanentes de coordenação que sejam relativamente imunes às flutuaçôes dos ciclos políticos. De forma associada, o accountability favoreceria a continuidade da formulação e da implementação desse tipo de política.

Em políticas de infraestrutura energética, também enfocando a capacidade de coordenação, Santana (2016) analisou as condições físicas, de financiamento e de sustentação burocrática nos BRICs. Testou algumas hipóteses acerca do papel da estrutura nacional de finanças e procurou demonstrar as vantagens do sistema coordenado por crédito bancário, como instrumento para superar as defasagens tecnológicas do regime produtivo.
Dois tipos de capacidades se destacam aqui, a de coordenação (entre o governo central e as esferas de poder subnacionais, e entre o governo central e o empresariado) e a de regulação (criação de normas específicas).

Examinando a política ambiental, Fonseca (2016) investigou a adoção de procedimentos de licenciamento ambiental no Brasil, na Índia e na China na área de construção de barragens e geraçáo de infraestrutura hidrelétrica. Para isso, enfatizou a capacidade de coordenação, tanto entre as agências governamentais quanto entre o Estado e a sociedade. $\mathrm{O}$ autor sustenta que a coordenação intragovernamental, em simultâneo às habilidades de defesa e promoção de direitos minoritários, seria condição necessária para a concretização de políticas promotoras de desenvolvimento ambiental sustentável.

A capacidade de coordenaçáo teve grande destaque nas políticas industrial, de infraestrutura energética e ambiental. Como visto, esses tipos de políticas exigiriam maior grau coordenação, uma vez que normalmente são planejadas para o longo prazo, pois, além de demandar um elevado investimento inicial, não trazem retorno imediato, estando sujeitas às flutuaçôes dos ciclos políticos. Logo, a capacidade de coordenação conformaria um instrumento para superar essas barreiras e, conjuntamente com as capacidades burocrática e relacional, oportunizaria a continuidade da formulação e da implementação de políticas nessas áreas.

No que tange às políticas de trabalho $e$ seguridade social, Lanzara (2016) examinou os sistemas de proteção social da África do Sul, da Argentina e do Brasil, destacando os diferentes graus de articulação entre as políticas previdenciárias e de proteção ao trabalho. $\mathrm{O}$ autor buscou averiguar como os países vêm construindo ou mobilizando 
a capacidade estatal no campo da regulação pública do trabalho e da previdência social, diante dos desafios postos pela globalização econômica.

Envolvendo a política social, Bichir (2016) estudou as principais condiçóes que permitiram o desenvolvimento de programas nacionais de transferência de renda no âmbito dos sistemas de proteção social do Brasil, da Argentina e da África do Sul. A autora enfatizou as condiçôes político-institucionais do surgimento e desenvolvimento desses programas, bem como suas articulações com outras políticas sociais. A investigação acionou os conceitos de capacidades: política - opção pela alternativa da transferência de renda associada a distintas estratégias para angariar apoio; administrativa/ burocrática - burocracia voltada exclusivamente ao desenvolvimento social e insulada de interesses; e de coordenação - entre as instituições responsáveis pela área de desenvolvimento social e aquelas a cargo de outras políticas sociais, como educação, saúde e geração de emprego e renda. De outro ângulo, Steffen (2017) observou a relação entre os Estados e os Bancos Multilaterais de Desenvolvimento com o propósito de verificar se as capacidades estatais, predominantemente a burocrática, seriam determinantes para a decisão de alocação de recursos destinados ao financiamento de projetos sociais na América Latina e no Caribe. Como proxy da capacidade estatal, Steffen (2017) utilizou a tipologia de welfare gaps, isto é, a diferença entre as necessidades no âmbito social que a populaçáo apresenta e a habilidade do governo em atendê-las. Para as políticas sociais, o destaque recaiu sobre as capacidades: política - como forma de garantir apoio, minimizar a resistência dos atores políticos e construir consensos; de coordenaçáo - considerando a intersetoriedade demandada; e burocrática - na forma da garantia de corpo administrativo exclusivo e insulado para a execução da política.

Tratando-se da política de comércio exterior e de cooperação internacional, Anastasia e Las Casas (2016) salientaram as capacidades estatais relacionadas à cooperação internacional bilateral entre Brasil e China e entre Brasil e África do Sul. Partiram do pressuposto de que as instituiçóes políticas afetam o comportamento dos atores, assim como a dinâmica de interação e os resultados do jogo. Utilizaram como lente de análise a capacidade de cooperação, entendendo que capacidades [diversas] semelhantes no nível doméstico contribuiriam para a cooperação no nível internacional. Já Leopoldi (2016) analisou as mudanças no formato do capitalismo brasileiro nas duas últimas décadas. Tomou como unidade de análise as políticas de desenvolvimento voltadas para a internacionalização da economia, que envolviam diversas agências e ministérios bem como se tornaram parte da agenda da política externa e da diplomacia brasileiras. Mostrou como a agenda das últimas décadas tem visado à inserção do país na economia internacional por meio de uma açáo efetiva do Estado, mobilizando as capacidades burocráticas (criar e manter, nas agências governamentais, uma burocracia especializada e dotada de transparência e accountability), de coordenaçáo (mecanismos de coordenaçáo intraburocráticas) e relacionais (arenas de diálogo entre governo, empresários $\mathrm{e}$ trabalhadores). Vê-se que as políticas de comércio exterior, cooperação internacional e internacionalização da economia valorizam as capacidades relacional e de coordenação, uma vez que versam sobre os aspectos da interação complexa entre diversos atores - 
nacionais e internacionais, estatais, empresariais e societais - como condição para o funcionamento das políticas.

O Quadro 1 sintetiza os tipos de políticas estudadas, os autores e a dimensão enfatizada.

Por fim, podemos perceber que três tipos de capacidades receberam maior atenção nos estudos em foco. Em primeiro lugar está a dimensão burocrática, mobilizando a hipótese de que um quadro de profissionais qualificados, com perspectivas de carreira, que compartilham dada percepção acerca dos objetivos e da desejabilidade da intervenção, para remontar às ideias em Skocpol (1985), geraria impactos positivos no desenho, nos processos e nos resultados das políticas públicas. Em segundo lugar, agrupamos as dimensóes relacional e de coordenação, visto que abordam aspectos da interação como condição de bom funcionamento das políticas. E, em terceiro lugar, as capacidades política, de negociação e de construção de consensos. Dessa constatação, partimos para a exploração e especificação das dimensóes das capacidades.

\section{Dimensões da capacidade estatal}

Como vimos, as definiçóes de capacidades estatais podem ressaltar diferentes dimensóes. Um dos primeiros autores a elencar esses aspectos foi Mann (1993), que definiu quatro tipos de fontes de poder social: ideológica, econômica, militar e política - esta de domínio estatal. O Estado, por sua vez, exerceria dois tipos de poder sobre a sociedade: despótico e infraestrutural. O primeiro corresponde à intervenção do Estado na sociedade sem negociação institucionalizada. Já o poder infraestrutural remete à capacidade do Estado de introduzir-se na sociedade civil e implementar decisóes por todo o seu domínio territorial.
Por meio de uma revisão sistemática de literatura internacional, Cingolani (2013) identificou sete principais dimensões acionadas nos estudos sobre capacidade estatal. A primeira delas é a coercitiva/militar, que consiste na capacidade do Estado de monopolizar a administração do poder coercitivo. A segunda é a fiscal — capacidade de extrair recursos da sociedade, principalmente na forma de impostos, podendo também referir-se à eficiência nos gastos do governo (Dincecco, 2011). Aqui, um dos autores mais reconhecidos é Tilly (1975), que enfatizou a relação entre a capacidade fiscal e a construção de um aparato repressivo, voltado para a extração de recursos da sociedade. A terceira dimensão é a administrativa ou de implementação, que tem raízes na tradição weberiana, pautada na existência de uma burocracia profissional e insulada. Neste recorte, salientam-se os trabalhos de Evans e Rauch (1999) e, especificamente no Brasil, o de Souza (2016). A quarta é a transformativa ou de industrialização - capacidade de intervir no sistema produtivo e moldar a economia. A quinta é a relacional ou cobertura territorial, que "busca capturar até que ponto o Estado realmente permeia a sociedade e é capaz de internalizar interaçóes sociais dentro de suas açóes" (Cingolani, 2013, p. 31). A sexta dimensão é a legal, focando o papel do Estado em garantir compromissos firmados e a execuçáo de contratos. Por fim, tem-se a política, referindo-se ao nível de poder acumulado pelos líderes eleitos para induzir as prioridades políticas entre os diferentes atores institucionais (partidos, Congressos, Câmaras etc.).

Apesar de os autores apresentarem diversas dimensóes das capacidades estatais, Hendrix (2010) argumenta que três são mais exploradas: a militar, a administrativa 
Quadro 1 - Capacidade estatal no Brasil, tipos de políticas analisadas, autores e dimensáo enfatizada.

\begin{tabular}{|l|c|c|}
\hline Tema/tipo de política & Autor(a) & Dimensáo enfatizada \\
\hline Ambiental & Fonseca (2016) & Coordenação \\
\hline Burocracia & Souza (2016, 2017) & Burocrática \\
\hline Burocracia & Marenco, Strohschoen e Joner (2017) & Burocrática, Fiscal e Política \\
\hline Burocracia & Grin et al. (2018) & Burocrática, Política, Regulação e Fiscal \\
\hline Comércio Exterior & Anastasia e Las Casas (2016) & Legal, Relacional, Política e Burocrática \\
\hline Desenvolvimento & Gaitán e Boschi (2016) & Política e Relacional \\
\hline Desenvolvimento & Gomes (2016) & Relacional \\
\hline Desenvolvimento & Gomide e Pires (2012) & Política e Burocrática \\
\hline Desenvolvimento & Nunes (2018) & Política e Burocrática \\
\hline Industrial & Delgado (2016) & Coordenação \\
\hline Infraestrutura energética & Santana (2016) & Coordenaçáo e Regulação \\
\hline Inovação & Castro (2016) & Política, Burocrática e Relacional \\
\hline Inovação & Jaguaribe (2016) & Burocrática \\
\hline Internacionalização Econômica & Leopoldi (2016) & Burocrática, Coordenação e Relacional \\
\hline Social & Bichir (2016) & Política, Burocrática e Coordenação \\
\hline Social & Steffen (2017) & Burocrática e Fiscal \\
\hline Trabalho e Seguridade Social & Lanzara (2016) & Regulação \\
\hline
\end{tabular}

ou burocrática e a qualidade e coerência das instituiçôes políticas. Contudo, Hanson e Sigman (2013) acreditam que o universo do Estado tem, pelo menos, seis funçôes: manutenção da ordem, proteção dos direitos de propriedade, cumprimento de contrato, provisão de bens e serviços públicos, competência técnica e coordenação de informaçóes e medidas. Cingolani (2013), por sua vez, acredita que essas funçôes podem ser agrupadas em: extrativa, coercitiva e administrativa.

No Brasil, as dimensóes da capacidade estatal foram abordadas por Gomide (2016) e Souza (2017). Gomide (2016) propóe analisar a capacidade a partir dos aspectos: coercitivo, fiscal, administrativo, relacional, legal e político. A capacidade coercitiva diz respeito ao papel do Estado na manutençáo da ordem pública e na defesa do território. Essa dimensão pode ser encontrada em estudos sobre os "Estados frágeis, isto é, países caracterizados pelo fraco poder ou legitimidade de seus Estados para proteger seus cidadãos, deixando-os vulneráveis a eventos de risco como conflitos internos, violência, fome etc." (Gomide, 2016, p. 23). A capacidade fiscal enfoca o poder do Estado na extração de recursos da sociedade por meio da arrecadação de impostos. A capacidade administrativa ou burocrática envolve a habilidade de implementação das políticas públicas. Para tanto, seria necessária uma burocracia 
profissional dotada de recursos e de instrumentos necessários. A dimensão relacional concerne às habilidades das burocracias estatais de se conectarem com os diversos grupos da sociedade. Dessa dimensão "adviria a capacidade dos governos de mobilizar recursos políticos, prestar contas e internalizar informaçôes necessárias para a efetividade de suas açôes" (Gomide, 2016, p. 23). A dimensão legal ou regulatória tange à capacidade para definir e garantir as regras que conformam as interaçóes entre os atores; está relacionada à garantia dos direitos de propriedade e dos contratos, bem como à regulação da atividade econômica. Por último, a capacidade política ou de conduçáo (steering capacity), correspondendo ao poder de agenda ou à faculdade dos governos eleitos de fazer valer suas prioridades. Ela evidencia tanto as "competências de planejamento estratégico e fixação de objetivos de longo prazo quanto o poder de veto de atores político-institucionais sobre as decisões do Poder Executivo" (Gomide, 2016, p. 23).

Já Souza (2017) sustenta que o conceito de capacidade estatal incorpora quatro dimensôes; três delas são similares às apresentadas por Gomide (2016): a política, a legal e a organizacional/administrativa, às quais agrega a capacidade de políticas públicas. Nas palavras da autora,

o componente político diz respeito às "regras do jogo" que regulam o comportamento político, societal e econômico. O componente legal diz respeito às regras jurídicas que regulam o comportamento dos atores e das instituições. O componente organizacionalladministrativo remete à capacidade de prover bens e serviços com eficiência. Por fim, o componente de políticas públicas, diz respeito a instituiçôes e estratégias que influenciam decisōes sobre políticas, sua formulação e execuçáo. Esse componente incorpora, entre outros, a construçáo de capacidade burocrática e o grau de profissionalizaçáo da burocracia para investigar as condições em que políticas são formuladas e executadas. Contudo, uma das mais importantes ressalvas sobre a capacidade do Estado é sua desigualdade ou variedade entre áreas de políticas públicas (Souza, 2017, p. 31, grifo dos autores).

Enfim, percebe-se que os estudos são variados e acabam convergindo para a delimitação dos tipos de dimensôes mais valorizados da capacidade estatal. Para ilustrar, o Quadro 2 traz os principais conceitos de capacidade estatal encontrados na literatura e a dimensão enfatizada pelos autores.

Após estabelecer as principais dimensóes propostas por autores nacionais e internacionais, bem como trazer os principais conceitos de capacidade estatal e relacionar com a dimensão enfatizada por estes, resta ainda discutir quais as formas de medi-las presentes na literatura, conforme segue.

\section{Formas de medir a capacidade estatal}

O tópico visa a discutir as formas de medir as capacidades estatais encontradas na literatura. Para tanto, foram analisados estudos internacionais e nacionais, pioneiros e recentes, relevantes para o tema. $\mathrm{Ou}-$ tros trabalhos, que não foram descritos, compuseram o Quadro 3, do estado da arte sobre a forma de mensuração dessas capacidades.

O primeiro trabalho que se debruçou sobre como medir a capacidade estatal foi o de Geddes (1994). Ela enfatizou a capacidade administrativa/burocrática desenvolvendo o índice estratégico de 
Quadro 2 - Conceituaçáo de capacidade estatal na literatura e relaçáo com a dimensão enfatizada.

\begin{tabular}{|c|c|c|}
\hline Autor(es) & Conceituaçáo de capacidade estatal & $\begin{array}{l}\text { Dimensáo } \\
\text { enfatizada }\end{array}$ \\
\hline $\begin{array}{l}\text { Huntington } \\
(1968)\end{array}$ & $\begin{array}{l}\text { A capacidade do Estado é a durabilidade, complexidade, adaptabilidade, } \\
\text { coerência e autonomia de organizaçáo e procedimentos. }\end{array}$ & $\begin{array}{l}\text { Burocrática/ } \\
\text { Administrativa }\end{array}$ \\
\hline $\begin{array}{l}\text { Tilly }(1975, \\
\text { p. 40) }\end{array}$ & $\begin{array}{l}\text { No processo de formação do Estado na Europa Ocidental, o nível do } \\
\text { Estado é definido pela construçáa de um aparelho de Estado repressivo } \\
\text { que "efetivamente extraia os recursos necessários da populaçáo local e } \\
\text { verifique seus esforços para resistir à extraçáo de recursos". }\end{array}$ & $\begin{array}{l}\text { Coercitiva e } \\
\text { Fiscal }\end{array}$ \\
\hline $\begin{array}{l}\text { Skocpol } \\
(1979)\end{array}$ & $\begin{array}{l}\text { A integridade soberana e o controle administrativo-militar estável de } \\
\text { um determinado território são condiçóes prévias para a capacidade de } \\
\text { qualquer estado em implementar políticas. Além disso, funcionários leais } \\
\text { e qualificados e recursos financeiros abundantes sáo básicos para garantir a } \\
\text { eficácia de todos os objetivos. }\end{array}$ & $\begin{array}{l}\text { Burocrática/ } \\
\text { Administrativa }\end{array}$ \\
\hline $\begin{array}{l}\text { Skocpol } \\
\text { (1985, p. 9) }\end{array}$ & $\begin{array}{l}\text { Capacidade estatal é a capacidade de "implementar objetivos oficiais, } \\
\text { especialmente sobre a oposiçáo real ou potencial de grupos sociais } \\
\text { poderosos ou diante de circunstâncias socioeconômicas recalcitrantes". }\end{array}$ & $\begin{array}{l}\text { Burocrática/ } \\
\text { Administrativa, } \\
\text { Fiscal e } \\
\text { Coercitiva }\end{array}$ \\
\hline $\begin{array}{l}\text { Rueschemeyer } \\
\text { e Evans } \\
(1985)\end{array}$ & $\begin{array}{l}\text { Eficácia da intervenção estatal na economia. A intervenção } \\
\text { efetiva requer uma burocracia capaz e boa coordenação e } \\
\text { coerência entre as organizaçóes do Estado. }\end{array}$ & $\begin{array}{l}\text { Transformativa } \\
\text { e Administrativa }\end{array}$ \\
\hline Levi (1988) & A capacidade do Estado de fornecer bens coletivos aumentando a receita. & Fiscal \\
\hline Evans (1995) & $\begin{array}{l}\text { A chave para a capacidade estatal é a autonomia inserida: uma combinaçấo } \\
\text { de poder de insulamento administrativo e certo nível de inserçấo do } \\
\text { Estado na estrutura produtiva. }\end{array}$ & $\begin{array}{l}\text { Relacional, } \\
\text { Transformativa } \\
\text { e Burocrática }\end{array}$ \\
\hline $\begin{array}{l}\text { Mann (1986; } \\
\text { 1993, p. 59) }\end{array}$ & $\begin{array}{l}\text { O poder despótico é a "gama de açóes que a elite estatal está habilitada } \\
\text { a empreender sem negociaçóes rotineiras e institucionalizadas com } \\
\text { grupos da sociedade civil". O poder infraestrutural, por outro lado, "é } \\
\text { a capacidade de penetrar efetivamente na sociedade civil e implementar } \\
\text { decisôes políticas ou usar recursos em toda regiáo". }\end{array}$ & $\begin{array}{l}\text { Administrativa, } \\
\text { Relacional } \\
\text { e Cobertura } \\
\text { Territorial }\end{array}$ \\
\hline $\begin{array}{l}\text { Midgal (1988, } \\
\text { prólogo) }\end{array}$ & $\begin{array}{l}\text { Capacidades são "as habilidades dos líderes para usar as agências do Estado } \\
\text { para fazer com que as pessoas na sociedade façam o que querem que elas } \\
\text { façam". Ou para "alcançar os tipos de mudanças na sociedade que seus } \\
\text { líderes buscavam através do planejamento, políticas e açōes". Estes incluem } \\
\text { "as capacidades para penetrar na sociedade, regular as relaçôes sociais, extrair } \\
\text { recursos e apropriar ou usar recursos de maneiras determinadas". }\end{array}$ & $\begin{array}{l}\text { Relacional } \\
\text { e Cobertura } \\
\text { Territorial }\end{array}$ \\
\hline $\begin{array}{l}\text { Weaver e } \\
\text { Rockman } \\
(1993)\end{array}$ & $\begin{array}{l}\text { Listam dez capacidades estatais universais, dentre as quais servem para } \\
\text { manter as prioridades; inovar quando as políticas antigas falharem e } \\
\text { garantir a implementação efetiva das políticas. }\end{array}$ & $\begin{array}{l}\text { Política e } \\
\text { Relacional }\end{array}$ \\
\hline $\begin{array}{l}\text { Geddes } \\
(1994)\end{array}$ & $\begin{array}{c}\text { A capacidade de implementar políticas iniciadas pelo Estado depende da } \\
\text { capacidade de tributar, coagir, moldar os incentivos enfrentando os setores } \\
\text { privados e tomar decisōes burocráticas efetivas durante a implementaçấo. } \\
\text { Todas essas habilidades dependem, por sua vez, da existência de } \\
\text { organizaçôes burocráticas efetivas. }\end{array}$ & $\begin{array}{c}\text { Fiscal, } \\
\text { Coercitiva e } \\
\text { Administrativa }\end{array}$ \\
\hline
\end{tabular}

Continua... 
Quadro 2-Continuação.

\begin{tabular}{|c|c|c|}
\hline Autor(es) & Conceituaçáo de capacidade estatal & $\begin{array}{l}\text { Dimensáo } \\
\text { enfatizada }\end{array}$ \\
\hline $\begin{array}{l}\text { World Bank } \\
(1997)\end{array}$ & $\begin{array}{c}\text { A capacidade estatal é definida como: a capacidade de empreender e } \\
\text { promover açóes coletivas de forma eficiente. }\end{array}$ & $\begin{array}{l}\text { Política e } \\
\text { Relacional }\end{array}$ \\
\hline $\begin{array}{l}\text { Weiss }(1998, \\
\text { p. } 7)\end{array}$ & $\begin{array}{l}\text { A capacidade de "conceber e implementar políticas que aumentam } \\
\text { o excedente de investimento da sociedade ou, como mencionado } \\
\text { anteriormente, a capacidade de coordenar as mudanças industriais para } \\
\text { enfrentar o contexto em mudança da concorrência internacional". }\end{array}$ & Transformativa \\
\hline $\begin{array}{l}\text { Evans e Rauch } \\
\text { (1999) }\end{array}$ & $\begin{array}{l}\text { O "nível Weberiano" é o grau em que as agências fundamentais do Estado } \\
\text { são caracterizadas pelo recrutamento meritocrático e oferecem carreiras } \\
\text { previsíveis e de longo prazo. }\end{array}$ & $\begin{array}{c}\text { Burocrática/ } \\
\text { Administrativa }\end{array}$ \\
\hline $\begin{array}{l}\text { Centeno } \\
(2002)\end{array}$ & $\begin{array}{l}\text { A capacidade estatal é a capacidade da autoridade política relevante para } \\
\text { fazer valer seus desejos. }\end{array}$ & $\begin{array}{l}\text { Administrativa e } \\
\text { Política }\end{array}$ \\
\hline $\begin{array}{l}\text { Fearon e } \\
\text { Laitin }(2003 \text {, } \\
\text { p. } 80)\end{array}$ & $\begin{array}{l}\text { A capacidade do Estado é "a capacidade policial e militar do governo e o } \\
\text { alcance das instituiçốes governamentais nas áreas rurais". }\end{array}$ & $\begin{array}{l}\text { Coercitiva e } \\
\text { Cobertura } \\
\text { Territorial }\end{array}$ \\
\hline $\begin{array}{l}\text { Fukuyama } \\
(2004, \text { p. } 7)\end{array}$ & $\begin{array}{l}\text { Capacidade estatal como "a capacidade dos Estados de planejar e executar } \\
\text { políticas e aplicar as leis de forma limpa e transparente". }\end{array}$ & $\begin{array}{l}\text { Administrativa } \\
\text { e Legal }\end{array}$ \\
\hline $\begin{array}{l}\text { Charron e } \\
\text { Lapuente } \\
(2010)\end{array}$ & $\begin{array}{l}\text { A capacidade de um Estado para realizar suas atividades de } \\
\text { forma eficiente e sem corrupçâo. }\end{array}$ & $\begin{array}{c}\text { Burocrática/ } \\
\text { Administrativa }\end{array}$ \\
\hline $\begin{array}{l}\text { Acemoglu, } \\
\text { Ticchi e } \\
\text { Vindigni } \\
(2006 ; 2011)\end{array}$ & $\begin{array}{l}\text { A eficiência do Estado envolve as habilidades de uma autoridade central } \\
\text { para monitorar burocratas. }\end{array}$ & Política e Legal \\
\hline $\begin{array}{l}\text { Besley e } \\
\text { Persson (2007; } \\
\text { 2009) }\end{array}$ & $\begin{array}{l}\text { Alta capacidade é um bom cumprimento dos direitos } \\
\text { de propriedade e contratos. }\end{array}$ & Legal e Fiscal \\
\hline $\begin{array}{l}\text { Bäck e } \\
\text { Hadenius } \\
(2008)\end{array}$ & $\begin{array}{l}\text { A capacidade do Estado é multidimensional: monopólio dos militares, } \\
\text { monopólio da capacidade fiscal, alta autonomia burocrática, monopólio } \\
\text { da capacidade legal. }\end{array}$ & $\begin{array}{l}\text { Coercitiva, } \\
\text { Fiscal, } \\
\text { Administrativa } \\
\text { e Legal }\end{array}$ \\
\hline Soifer (2008) & $\begin{array}{l}\text { Três abordagens para o poder infraestrutural: a) relaçáo entre o } \\
\text { Estado e suas instituiçôes radiais; b) capacidade da administraçáo central; } \\
\text { c) alcance territorial do Estado. }\end{array}$ & $\begin{array}{l}\text { Relacional, } \\
\text { Administrativa } \\
\text { e Cobertura } \\
\text { territorial }\end{array}$ \\
\hline $\begin{array}{l}\text { Besley e } \\
\text { Persson } \\
(2008)\end{array}$ & $\begin{array}{l}\text { No centro da capacidade estatal está a capacidade de cobrar impostos para } \\
\text { financiar bens públicos e fazer transferências. }\end{array}$ & Fiscal \\
\hline $\begin{array}{l}\text { Robinson } \\
(2008)\end{array}$ & Coordenação do conhecimento em locais fragmentados de governança. & Relacional \\
\hline
\end{tabular}

Continua... 
Quadro 2 - Continuação.

\begin{tabular}{|c|c|c|}
\hline Autor(es) & Conceituaçáo de capacidade estatal & $\begin{array}{l}\text { Dimensáo } \\
\text { enfatizada }\end{array}$ \\
\hline $\begin{array}{l}\text { Cárdenas } \\
(2010)\end{array}$ & $\begin{array}{l}\text { A capacidade estatal é definida como a capacidade do } \\
\text { Estado de gerar receita fiscal. }\end{array}$ & Fiscal \\
\hline Kocher (2010) & $\begin{array}{l}\text { Cinco características de Estados fortes que são viáveis: a) centralização } \\
\text { e unificação; b) capacidade de riqueza e tributação; c) burocracia } \\
\text { profissional; d) poucas restriçôes do regime; e) exército forte. }\end{array}$ & $\begin{array}{l}\text { Coercitiva, } \\
\text { Fiscal, } \\
\text { Administrativa e } \\
\text { Política }\end{array}$ \\
\hline $\begin{array}{l}\text { DeRouen } e t \\
\text { al. }(2010)\end{array}$ & $\begin{array}{l}\text { A capacidade é a habilidade do estado de atingir os objetivos que persegue, } \\
\text { possivelmente diante da resistência dos atores dentro do Estado. }\end{array}$ & Coercitiva \\
\hline $\begin{array}{l}\text { McBride, } \\
\text { Milante e } \\
\text { Skaperdas } \\
(2011)\end{array}$ & $\begin{array}{l}\text { Capacidade estatal denota o nível de compromisso que pode ser } \\
\text { alcançado, mas que pode mudar ao longo do tempo a influência de } \\
\text { pessoas de fora, bem como as açóes dos principais atores nos países. }\end{array}$ & Legal \\
\hline $\begin{array}{l}\text { Dincecco e } \\
\text { Prado (2012) }\end{array}$ & $\begin{array}{l}\text { A capacidade fiscal é a capacidade dos Estados } \\
\text { de aumentar as receitas fiscais. }\end{array}$ & Fiscal \\
\hline $\begin{array}{l}\text { Besley e } \\
\text { Persson } \\
(2011)\end{array}$ & $\begin{array}{l}\text { Capacidade institucional do Estado para levar a cabo diversas políticas que } \\
\text { oferecem benefícios e serviços às empresas domésticas. }\end{array}$ & $\begin{array}{l}\text { Coercitiva, } \\
\text { Legal e Fiscal }\end{array}$ \\
\hline $\begin{array}{l}\text { Hamm, King } \\
\text { e Stuckler } \\
(2012)\end{array}$ & $\begin{array}{l}\text { A capacidade estatal é entendida como a existência } \\
\text { do poder infraestrutural: a capacidade do Estado de } \\
\text { penetrar na sociedade e realizar seus objetivos. }\end{array}$ & $\begin{array}{l}\text { Infraestrutural } \\
\text { e Cobertura } \\
\text { Territorial }\end{array}$ \\
\hline $\begin{array}{l}\text { Knutsen } \\
(2013)\end{array}$ & $\begin{array}{l}\text { A capacidade estatal é entendida como a implementaçấo } \\
\text { bem-sucedida de políticas públicas por meio de uma } \\
\text { burocracia seguidora das leis e eficiente. }\end{array}$ & $\begin{array}{l}\text { Administrativa, } \\
\text { Legal e Fiscal }\end{array}$ \\
\hline $\begin{array}{l}\text { Fukuyama } \\
(2013)\end{array}$ & $\begin{array}{l}\text { A capacidade é definida pelos insumos para a burocracia, como o nível de } \\
\text { educação dos funcionários do governo. }\end{array}$ & $\begin{array}{l}\text { Burocrática/ } \\
\text { Administrativa }\end{array}$ \\
\hline $\begin{array}{l}\text { Souza (2016, } \\
\text { p. 51) }\end{array}$ & $\begin{array}{c}\text { Capacidade estatal é definida como o "conjunto de instrumentos e } \\
\text { instituiçôes de que dispố o Estado para estabelecer objetivos, } \\
\text { transformá-los em políticas e implementá-las". }\end{array}$ & $\begin{array}{l}\text { Burocrática/ } \\
\text { Administrativa }\end{array}$ \\
\hline $\begin{array}{l}\text { Bichir }(2016, \\
\text { p. 26) }\end{array}$ & $\begin{array}{c}\text { As capacidades do Estado "derivam não só das competências de } \\
\text { formulação e implementação de suas políticas, mas também da } \\
\text { construção de apoio à agenda entre os atores sociais, } \\
\text { políticos e econômicos relevantes". }\end{array}$ & $\begin{array}{l}\text { Burocrática/ } \\
\text { Administrativa e } \\
\text { Relacional }\end{array}$ \\
\hline $\begin{array}{l}\text { Jaguaribe } \\
(2016, \text { p. 26) }\end{array}$ & $\begin{array}{l}\text { As capacidades estatais abarcam tanto as burocracias e as instâncias de ação } \\
\text { do Estado como a dinâmica de atuaçáo política — isto é, a "capacidade } \\
\text { de formular políticas, construir e coordenar consensos, e abrir espaços de } \\
\text { política pública (policy spaces) entre objetivos e oportunidades". }\end{array}$ & $\begin{array}{l}\text { Burocrática/ } \\
\text { Administrativa, } \\
\text { Política e } \\
\text { Relacional }\end{array}$ \\
\hline
\end{tabular}

Fonte: elaboração própria com base em Cingolani (2013). A autora não explanou sobre a forma de enquadramento das pesquisas nas dimensóes enfatizadas. Contudo, o método utilizado foi localizar em cada pesquisa a dimensão apresentada pelos próprios autores. 
nomeação (appointment strategy index) que enfoca o critério de nomeaçóes executivas, se partidário ou baseado em competências. Além disso, a autora mediu a capacidade estatal a partir do número de reformas administrativas.

No trabalho de Evans e Rauch (1999) foi examinada a capacidade administrativa/ burocrática, medida por meio de uma escala weberiana composta por indicadores de recrutamento meritocrático e evolução previsível para a carreira profissional. O recrutamento é baseado em uma combinação de educação e verificação. O indicador evolução previsivel para a carreira profissional expressa a oferta de recompensas tangíveis e intangíveis a longo prazo para os funcionários de carreira, objetivando não apenas o aumento da competência e da coerência corporativa, mas também a redução da atratividade dos retornos rápidos por meio de práticas corruptas. Os autores verificaram a existência de uma associação positiva entre a escala weberiana e o crescimento econômico, ou seja, quanto maior o score na escala (recrutamento e salários e carreira), maior o crescimento econômico (em termos PIB per capita).

Mais recentemente, na literatura nacional, Souza $(2015,2016,2017)$ elaborou o índice da qualidade da burocracia (IQB) para comparar a capacidade burocrática/administrativa no Brasil e na Argentina. O índice foi desagregado em quatro dimensões que buscam mostrar diferenças entre agências e políticas, são elas:

- Recrutamento: proporção de servidores com contrato temporário (IR1) e proporção de servidores requisitados (IR2);
- Formação: proporção de servidores concursados generalistas (IF1) e proporçáo de servidores concursados especialistas (IF2);

- Promoção interna: ocupação de cargos comissionados por servidores de carreia (IP1);

- Accountability: proporção de servidores demitidos por processos administrativos (IA1).

$\mathrm{O} \mathrm{IQB}^{3}$ "representa a soma dos índices calculados para cada variável, multiplicados pelos correspondentes pesos" (Souza, 2016, p. 67-68). Para a autora, a qualidade da burocracia, medida pelo IQB, está relacionada diretamente à eficácia das políticas públicas, isto é, onde a qualidade é insatisfatória, a política tende a não funcionar.

Já Marenco, Strohschoen e Joner (2017), sob o prisma da capacidade fiscal, política e administrativa/burocrática, buscaram investigar em que medida municípios com burocracias profissionalizadas tiveram melhores condiçóes para aproveitar a transferência de responsabilidades e autoridade política e administrativa, ampliando seu potencial para tributar e implementar políticas públicas. Para isso, examinaram a participação do Imposto Predial e Territorial Urbano (IPTU) na arrecadação municipal, relacionando alteraçóes com três variáveis: tamanho do município; ciclos partidários e eleitorais e perfil; e qualidade da burocracia municipal. Em relação ao tamanho dos municípios, a hipótese é de que cidades de pequeno porte e baixa população apresentariam base tributária mais reduzida, contudo, ao mesmo tempo, teriam custos de transação política mais elevados, decorrentes da proximidade pessoal entre autoridades e potenciais contribuintes.

$3 \mathrm{IQB}=(1-\mathrm{IR} 1) \times p_{1}+(1-\mathrm{IR} 2) \times p_{2}+\mathrm{IF} 1 \times p_{3}+\mathrm{IF} 2 \times p_{4}+\mathrm{IP} 1$ ' $\mathrm{x} p_{5}+(1-\mathrm{IA} 1) \times p_{6}$, em que $p$ representa os pesos de cada indicador (SOUZA, 2016, p. 72). 
A influência dos ciclos partidários e eleitorais e perfil se daria pelo fato de municípios com carga fiscal redistributiva mais elevada, com maior taxação sobre patrimônio imobiliário e visando a reduzir a pressão fiscal sobre a propriedade, terem optado por eleger prefeitos mais liberais ou conservadores; por outro lado, existiria maior margem de tolerância para experimentação. Por fim, a qualidade da burocracia municipal foi subdividida em: autonomia, correspondendo a ingresso por concursos ou seleçôes públicas e garantia de carreiras profissionais a longo prazo; e capacidade, identificada por procedimentos meritocráticos de avaliação de desempenho e reconhecimento de competência técnica, sendo empregada para o estudo a combinação "estatutário" com "formação superior". Com resultado, esses autores constataram que quanto mais profissionalizadas são as administraçóes municipais, maior é a chance do incremento da arrecadaçấo do imposto patrimonial (Marenco; Strohschoen; Joner, 2017).

Ainda na literatura nacional, Steffen (2017), utilizando a base de dados do Banco Mundial, testou a relação entre a capacidade estatal (em países latino-americanos e do Caribe) e a alocação dos recursos financeiros de um Banco Multilateral de Desenvolvimento. Para essa análise, a autora dividiu as variáveis da capacidade estatal em dois blocos:

- Projetos financiados pelo Banco, incluindo informaçóes básicas sobre país, ano de aprovaçáo do financiamento, origem e volume de recursos concedidos, classificaçóes setoriais e temáticas, equipe, agência implementadora, entre outros;
- Capacidade estatal, tomando como pro$x y$ o welfare gap.

O estudo concluiu que há relação entre a capacidade estatal e a distribuiçáo do financiamento do Banco Mundial em política social, no sentido de que quanto maior a capacidade estatal dos países, maior a sua quantidade de aportes financeiros obtida.

O Quadro 3 traz alguns trabalhos que tentaram medir a capacidade estatal, seja criando a própria medida ou por meio de formas disponíveis na literatura.

Além dos autores já apontados, outros se debruçaram sobre como medir as capacidades estatais, como, por exemplo, Acemoglu, Johnson e Robinson (2001), que, utilizando dados do ICRG-PRS Group, empregaram a capacidade legal como forma de avaliar o risco de expropriaçáo e repúdio a contratos governamentais ${ }^{4}$. Com essa mesma fonte de dados, Bäck e Hadenius (2008) mediram a capacidade estatal administrativa/burocrática para a qualidade da burocracia e o controle da corrupção; Besley e Persson (2009) desenvolvem uma abordagem para estudar a influência das capacidades legal e fiscal na regulação econômica e na tributação; Hendrix (2010) avaliou a qualidade burocrática e a medida de expropriação de risco etc.

De acordo com Cingolani (2013, p. 38), existem três tipos de abordagens para medir capacidade estatal: "Escolher uma medida genérica, escolher uma definição limitada e unidimensional com proxies correspondentes ou escolher um composto multidimensional de índices (ou várias medidas para cada dimensão)". Das três abordagens propostas pela autora, a primeira é

4 International Country Risk Guide (ICRG) é uma importante base de dados contendo pesquisas em diversos países e áreas da política. 
Quadro 3 - Formas de medir capacidade estatal na literatura.

\begin{tabular}{|c|c|c|c|}
\hline Autor(es) & $\begin{array}{c}\text { Medidas de } \\
\text { capacidade estatal }\end{array}$ & Fonte & $\begin{array}{c}\text { Dimensão da } \\
\text { capacidade estatal }\end{array}$ \\
\hline Geddes (1994) & $\begin{array}{l}\text { Índice de Estratégia de Nomeação: um } \\
\text { indicador composto que mede se os critérios } \\
\text { para nomeações executivas são partidários } \\
\text { ou baseados em competências. Além disso, a } \\
\text { capacidade estatal é aproximada pelo número } \\
\text { de reformas administrativas. }\end{array}$ & $\begin{array}{l}\text { Elaboração da } \\
\text { autora }\end{array}$ & $\begin{array}{l}\text { Burocrática/ } \\
\text { Administrativa }\end{array}$ \\
\hline Evans e Rauch (1999) & $\begin{array}{l}\text { Nível weberiano do Estado: } \\
\text { medindo recrutamento meritocrático, } \\
\text { arranjos salariais e carreiras. }\end{array}$ & $\begin{array}{l}\text { Elaboração dos } \\
\text { autores }\end{array}$ & $\begin{array}{l}\text { Burocrática/ } \\
\text { Administrativa }\end{array}$ \\
\hline $\begin{array}{l}\text { Acemoglu, Johnson e } \\
\text { Robinson (2001) }\end{array}$ & $\begin{array}{l}\text { Restriçóes ao Executivo: avaliação da } \\
\text { pesquisa sobre risco de expropriação e } \\
\text { repúdio a contratos governamentais. }\end{array}$ & ICRG-PRS Group & Legal \\
\hline Centeno (2002) & Data do primeiro Censo Nacional & $\begin{array}{l}\text { Goyer, Domschke e } \\
\text { Draaijer (1983) }\end{array}$ & Infraestrutural/ \\
\hline & Densidade ferroviária em 1990 & Mitchel (1983) & \\
\hline $\begin{array}{l}\text { Bockstette, Chanda e } \\
\text { Puttermann (2002) }\end{array}$ & Statehist5: Índice de Antiguidade Estatal & $\begin{array}{l}\text { Elaboração } \\
\text { dos autores }\end{array}$ & Genérica \\
\hline Fearon e Laitin (2003) & Log do PIB per capita & & Genérica \\
\hline Bäck e Hadenius (2008) & $\begin{array}{l}\text { Qualidade da burocracia e } \\
\text { controle da corrupção }\end{array}$ & ICRG-PRS Group & $\begin{array}{l}\text { Burocrática/ } \\
\text { Administrativa }\end{array}$ \\
\hline \multirow{3}{*}{ Soifer (2008) } & $\begin{array}{c}\text { Capacidade nacional sobre receitas e despesas } \\
\text { nacionais na Europa Ocidental }\end{array}$ & $\begin{array}{l}\text { Mann }(1993) \text { e } \\
\text { Straus (2006) }\end{array}$ & $\begin{array}{c}\text { Burocrática/ } \\
\text { Administrativa }\end{array}$ \\
\hline & $\begin{array}{l}\text { Variação territorial na capacidade do } \\
\text { Estado em forçar a conformidade }\end{array}$ & $\begin{array}{l}\text { Kalyvas (2006), } \\
\text { Goodwin }(2001) \text { e } \\
\text { Soifer }(2006)\end{array}$ & $\begin{array}{l}\text { Controle } \\
\text { Territorial }\end{array}$ \\
\hline & Efeitos da política estadual na identidade social & $\begin{array}{l}\text { Weber }(1976) \text { e } \\
\text { Vaughan (1997) }\end{array}$ & Relacional \\
\hline \multirow{3}{*}{ Besley e Persson (2008) } & $\begin{array}{c}\text { Cobrança de impostos como parte do } \\
\text { produto interno bruto (PIB) }\end{array}$ & \multirow{3}{*}{$\begin{array}{l}\text { Baunsgaard e } \\
\text { Keen }(2005)\end{array}$} & \multirow{3}{*}{ Fiscal/Extrativa } \\
\hline & Imposto de renda como parte do imposto total & & \\
\hline & Taxa de inflação média & & \\
\hline
\end{tabular}

Continua... 
Quadro 3 - Continuação.

\begin{tabular}{|c|c|c|c|}
\hline Autor(es) & $\begin{array}{l}\text { Medidas de } \\
\text { capacidade estatal }\end{array}$ & Fonte & $\begin{array}{l}\text { Dimensáo da } \\
\text { capacidade estatal }\end{array}$ \\
\hline \multirow{8}{*}{ Besley e Persson (2009) } & Taxa de crédito privado ao PIB & $\begin{array}{l}\text { King e Levine } \\
\text { (1993) }\end{array}$ & \multirow{3}{*}{ Legal } \\
\hline & Acesso ao crédito & Doing Business & \\
\hline & Proteção ao investidor & ICRG-PRS Group & \\
\hline & $\begin{array}{l}\text { Índice de políticas governamentais antidiversas } \\
\text { (soma de cinco indicadores diferentes) }\end{array}$ & \multirow{5}{*}{ IMF/WDI } & \multirow{5}{*}{ Fiscal/Extrativa } \\
\hline & $\begin{array}{l}\text { Menos um a parcela dos impostos comerciais } \\
\text { em impostos totais }\end{array}$ & & \\
\hline & $\begin{array}{l}\text { Menos um a parte do comércio e impostos } \\
\text { indiretos em impostos totais }\end{array}$ & & \\
\hline & Participação do imposto de renda sobre no PIB & & \\
\hline & Participação dos impostos no PIB & & \\
\hline \multirow{10}{*}{ Hendrix (2010) } & Pessoal militar per capita & $\begin{array}{c}\text { Correlates of War } \\
(\text { CoW }), \text { Material } \\
\text { Capabilities Dataset }\end{array}$ & Coercitiva \\
\hline & $\begin{array}{c}\text { Pesquisa sobre avaliação de qualidade } \\
\text { burocrática }\end{array}$ & \multirow{2}{*}{ ICRG-PRS Group } & \multirow{2}{*}{$\begin{array}{l}\text { Burocrática/ } \\
\text { Administrativa }\end{array}$} \\
\hline & Medidas de expropriação de risco & & \\
\hline & Exportaçôes de commodities & \multirow{2}{*}{ WDI } & $\begin{array}{l}\text { Burocrática/ } \\
\text { Administrativa }\end{array}$ \\
\hline & Imposto total/PIB & & Fiscal/Extrativa \\
\hline & $\begin{array}{l}\text { Capacidade política relativa: ratio da receita } \\
\text { fiscal real/receita fiscal esperada }\end{array}$ & $\begin{array}{c}\text { Kugler e Arbetman } \\
\text { (1997) }\end{array}$ & \\
\hline & $\begin{array}{l}\text { Níveis de produçáo de petróleo e reservas } \\
\text { comprovadas }\end{array}$ & $\begin{array}{c}\text { BP Statistical } \\
\text { Review of World } \\
\text { Energy and } \\
\text { Other Sources } \\
\text { (Humphreys, 2005) }\end{array}$ & Fiscal/Extrativa \\
\hline & $\begin{array}{l}\text { Coerência política entre características } \\
\text { democráticas e não democráticas }\end{array}$ & Polity 2 & \multirow{3}{*}{ Política } \\
\hline & $\begin{array}{l}\text { Recrutamento executivo; participaçáo } \\
\text { eleitoral e restriçōes a autoridade executiva }\end{array}$ & $\begin{array}{c}\text { Scalar Index of } \\
\text { Polities (SIP) (Gates } \\
\text { et al., 2006) }\end{array}$ & \\
\hline & Democracia política & Polity2 & \\
\hline
\end{tabular}

Continua... 
Quadro 3-Continuação.

\begin{tabular}{|c|c|c|c|}
\hline Autor(es) & $\begin{array}{c}\text { Medidas de } \\
\text { capacidade estatal }\end{array}$ & Fonte & $\begin{array}{c}\text { Dimensão da } \\
\text { capacidade estatal }\end{array}$ \\
\hline \multirow{6}{*}{ Fortin (2010) } & $\begin{array}{c}\text { Qualidade da provisão dos bens públicos consiste } \\
\text { em um índice de } 5 \text { itens (para a Europa) }\end{array}$ & & \\
\hline & Níveis de corrupção & $\begin{array}{l}\text { CPI-TI, Heritage } \\
\text { Foundation }\end{array}$ & $\begin{array}{l}\text { Burocrática/ } \\
\text { Administrativa }\end{array}$ \\
\hline & $\begin{array}{l}\text { Qualidade de proteção de direitos de } \\
\text { propriedade }\end{array}$ & $\begin{array}{l}\text { Heritage } \\
\text { Foundation }\end{array}$ & Legal \\
\hline & $\begin{array}{c}\text { Capacidade de tributação: ratio da receita } \\
\text { tributária no PIB }\end{array}$ & IMF & Fiscal/Extrativa \\
\hline & $\begin{array}{l}\text { Progresso na Reforma Infraestrutural, } \\
\text { indicadores de infraestrutura }\end{array}$ & EBRD & Infraestrutural \\
\hline & $\begin{array}{l}\text { Proporçáo de dinheiro náo monetário em relaçáo } \\
\text { a oferta monetária total (proporção de moeda em } \\
\text { relação ao dinheiro detido nos bancos) }\end{array}$ & $\begin{array}{l}\text { IMF } \\
\text { complementado } \\
\text { com EIU }\end{array}$ & Legal \\
\hline Thies (2010) & $\begin{array}{l}\text { Receita total/PIB; imposto total/PIB; } \\
\text { capacidade política relativa }\end{array}$ & $\begin{array}{c}\text { Johnson e } \\
\text { Rabinowitz (2005) }\end{array}$ & Fiscal/Extrativa \\
\hline Buhaug (2010) & $\begin{array}{l}\text { Capacidade política relativa: receita fiscal } \\
\text { real/receita fiscal esperada }\end{array}$ & $\begin{array}{l}\text { Kugler e Arbetman } \\
(1997)\end{array}$ & Fiscal/Extrativa \\
\hline \multirow{5}{*}{ Kocher $(2010)$} & O poder do exército & \multirow{5}{*}{$\begin{array}{l}\text { Proposição } \\
\text { Empírica }\end{array}$} & Coercitiva \\
\hline & Burocracia profissional & & $\begin{array}{l}\text { Burocrática/ } \\
\text { Administrativa }\end{array}$ \\
\hline & Capacidade de riqueza e tributação & & Fiscal/Extrativa \\
\hline & Redes rodoviárias & & Infraestrutural \\
\hline & Restriçōes do regime & & Política \\
\hline Hamm e King (2010) & $\begin{array}{c}\text { Taxa de homicídios como proxy para a } \\
\text { capacidade estatal }\end{array}$ & WHO & Genérica \\
\hline \multirow{8}{*}{ Cárdenas (2010) } & PIB dividido pelo total da receita & Baunsgaad e Keen & \multirow{3}{*}{ Fiscal } \\
\hline & PIB divido pela receita do imposto de renda & (2010) utilizando & \\
\hline & $\begin{array}{l}\text { Imposto total dividido pela } \\
\text { receita doméstica tributária }\end{array}$ & $\begin{array}{l}\text { países extraídos do } \\
\text { GFS produzido } \\
\text { pelo IMF. }\end{array}$ & \\
\hline & $\begin{array}{l}\text { Índice de confisco definitivo e } \\
\text { nacionalizaçáo forçada }\end{array}$ & ICRG-PRS Group & \multirow{5}{*}{$\begin{array}{l}\text { Burocrática/ } \\
\text { Administrativa }\end{array}$} \\
\hline & Facilidade em fazer negócios & Doing Business & \\
\hline & Efetividade governamental & WGI & \\
\hline & $\begin{array}{c}\text { Capacidade estatal — questionário } \\
\text { (Columbia) }\end{array}$ & $\begin{array}{l}\text { Universidade de } \\
\text { Colúmbia }\end{array}$ & \\
\hline & Medidas de capacidade estatal & $\begin{array}{c}\text { IADB (Berkman et } \\
\text { al., 2008) }\end{array}$ & \\
\hline
\end{tabular}

Continua... 
Quadro 3 - Continuação.

\begin{tabular}{|c|c|c|c|}
\hline Autor(es) & $\begin{array}{c}\text { Medidas de } \\
\text { capacidade estatal }\end{array}$ & Fonte & $\begin{array}{l}\text { Dimensáo da } \\
\text { capacidade estatal }\end{array}$ \\
\hline \multirow[t]{2}{*}{$\begin{array}{l}\text { Cárdenas, Eslava e } \\
\text { Ramírez (2011) }\end{array}$} & $\begin{array}{l}\text { Análise interpaíses: receita fiscal como } \\
\text { porcentagem do PIB; imposto de renda como } \\
\text { porcentagem do PIB; Índice de Qualidade do } \\
\text { Governo (média de lei e ordem, corrupçáo e } \\
\text { qualidade burocrática) }\end{array}$ & $\begin{array}{c}\text { Baunsgaard e } \\
\text { Keen (2010); IMF } \\
\text { (GFS); ICRG } \\
\text { Group }\end{array}$ & Fiscal/Legal \\
\hline & $\begin{array}{l}\text { Análise subnacional da Colômbia: receita } \\
\text { fiscal e gastos em estradas }\end{array}$ & $\begin{array}{l}\text { Drazen e Eslava } \\
\quad(2010)\end{array}$ & $\begin{array}{l}\text { Infraestrutural/ } \\
\text { Genérica }\end{array}$ \\
\hline \multirow{13}{*}{ Hanson e Sigman (2013) } & Qualidade da burocracia & $\begin{array}{l}\text { ICRG - PRS } \\
\text { Group }\end{array}$ & $\begin{array}{l}\text { Burocrática/ } \\
\text { Administrativa }\end{array}$ \\
\hline & Frequência do Censo & UN Statistics & $\begin{array}{l}\text { Controle } \\
\text { Territorial }\end{array}$ \\
\hline & Proporção de contrato de dinheiro intensivo & WDI Online & Legal \\
\hline & Densidade viária & $\begin{array}{l}\text { International Roads } \\
\text { Federation (WDI) }\end{array}$ & Infraestrutural \\
\hline & Índice de Antiguidade Estatal & $\begin{array}{c}\text { Bockstette, Chanda } \\
\text { e Puttermann } \\
(2002)\end{array}$ & Genérica \\
\hline & Estado de Direito & $\begin{array}{l}\text { ICRG - PRS } \\
\text { Group }\end{array}$ & Legal \\
\hline & Receita Tributável Total & \multirow{4}{*}{ IMF - WDI } & \multirow{4}{*}{ Fiscal/Extrativa } \\
\hline & Receita do imposto de renda & & \\
\hline & Receitas de impostos de produtos e serviços & & \\
\hline & Impostos em Comércio Internacional & & \\
\hline & Pessoal militar per capita & $\begin{array}{c}\text { Correlates of } \\
\text { War (CoW), } \\
\text { National Material } \\
\text { Capabilities v.3v02 }\end{array}$ & \multirow{3}{*}{ Coercitiva } \\
\hline & Gasto militar (\% dos gastos governamentais) & CoW e CNTS & \\
\hline & Militar em política & $\begin{array}{l}\text { ICRG - PRS } \\
\text { Group }\end{array}$ & \\
\hline
\end{tabular}

Continua... 
Quadro 3-Continuação.

\begin{tabular}{|c|c|c|c|}
\hline Autor(es) & $\begin{array}{c}\text { Medidas de } \\
\text { capacidade estatal }\end{array}$ & Fonte & $\begin{array}{l}\text { Dimensáo da } \\
\text { capacidade estatal }\end{array}$ \\
\hline \multirow{3}{*}{ Besley e Persson (2011) } & Índice de Fragilidade do Estado & Polity IV & Coercitiva \\
\hline & $\begin{array}{c}\text { Capacidade legal: Índice de Proteção de } \\
\text { Direito de Propriedade em } 1997\end{array}$ & $\begin{array}{l}\text { ICRG - PRS } \\
\text { Group }\end{array}$ & Legal \\
\hline & $\begin{array}{l}\text { Capacidade fiscal: Impostos totais dividido } \\
\text { pelo PIB em } 1999\end{array}$ & IMF & Fiscal \\
\hline \multirow{2}{*}{ Knutsen (2013) } & Índice da Qualidade da Burocracia & $\begin{array}{l}\text { ICRG - PRS } \\
\text { Group }\end{array}$ & $\begin{array}{l}\text { Burocrática/ } \\
\text { Administrativa }\end{array}$ \\
\hline & Statehist5 - Índice de Antiguidade Estatal & $\begin{array}{l}\text { Bockstette, Chanda e } \\
\text { Puttermann (2002) }\end{array}$ & Genérica \\
\hline \multirow{2}{*}{$\begin{array}{l}\text { Hamm, King e Stuckler } \\
\text { (2012) }\end{array}$} & $\begin{array}{l}\text { Mudanças nas despesas totais do governo entre } \\
1992 \text { e } 2000 \text { (despesas governamentais em } 2000 \text { em } \\
\text { dólares expressa como a divisão do ano de 1992) }\end{array}$ & WDI & Fiscal/Extrativa \\
\hline & $\begin{array}{l}\text { Questionário para captura da percepçáo } \\
\text { dos gerentes de empresas sobre eficiência } \\
\text { do Estado, conformidade de direitos de } \\
\text { propriedade e nível de corrupçáo }\end{array}$ & $\begin{array}{l}\text { EBDR Business } \\
\text { Environmental } \\
\text { and Enterprise } \\
\text { Performance Surveys }\end{array}$ & Genérica \\
\hline Dincecco e Katz (2016) & $\begin{array}{l}\text { Receitas governamentais }(1650-1913) \text { e } \\
\text { despesas governamentais }(1816-1913)\end{array}$ & Dincecco (2011) & Fiscal/Legal \\
\hline Dincecco e Prado (2012) & Divisão de impostos diretos & IMF & Fiscal \\
\hline Souza $(2015,2016)$ & $\begin{array}{c}\text { Índice da Qualidade da Burocracia } \\
\text { Brasileira e Argentina }\end{array}$ & $\begin{array}{c}\text { Elaboraçáo da } \\
\text { autora }\end{array}$ & $\begin{array}{l}\text { Burocrática/ } \\
\text { Administrativa }\end{array}$ \\
\hline $\begin{array}{l}\text { Marenco, Strohschoen e } \\
\text { Joner (2017) }\end{array}$ & $\begin{array}{l}\text { Examinam a participaçáo do IPTU na } \\
\text { arrecadaçáo municipal, relacionando } \\
\text { variaçóes na arrecadação do imposto } \\
\text { patrimonial com o tamanho dos municípios, } \\
\text { ciclos partidários e eleitorais e perfil e } \\
\text { qualidade da burocracia municipal. }\end{array}$ & $\begin{array}{l}\text { Elaboração dos } \\
\text { autores }\end{array}$ & $\begin{array}{c}\text { Fiscal e } \\
\text { Burocrática/ } \\
\text { Administrativa }\end{array}$ \\
\hline Steffen (2017) & $\begin{array}{l}\text { Testa a relaçáo entre a capacidade estatal, } \\
\text { em países latino-americanos e do Caribe, e } \\
\text { a alocação dos recursos financeiros de um } \\
\text { Banco Multilateral de Desenvolvimento. }\end{array}$ & $\begin{array}{l}\text { Elaboração da } \\
\text { autora }\end{array}$ & $\begin{array}{l}\text { Capacidade } \\
\text { Burocrática/ } \\
\text { Administrativa }\end{array}$ \\
\hline
\end{tabular}

ICRG-PRS: International Country Risk Guide/Political Risk Services; IMF/WDI: International Monetary Fund/World Development Indicators; EBRD: European Bank for Reconstruction and Development; EIU: Economist Intelligence Unit; WHO: World Health Organization; GFS: Government Finance Statistics; IMS: Information Management System; WGI: Worldwide Governance Indicators; IADB: Inter-American Development Bank; UN: United Nations; CoW: Correlates of War; CNTS: Cross-National Time-Series Data Archive; IPTU: Imposto Predial e Territorial Urbano. Fonte: elaboração própria com base em Cingolani (2013). A autora não explanou sobre a forma de enquadramento das pesquisas nas dimensôes das capacidades estatais, entretanto, a capacidade genérica foi entendida quando a própria autora não conseguiu encaixar em nenhuma dimensão ou em dimensōes específicas. 
mais frequentemente encontrada na literatura de economia e relaçóes internacionais. Nestas, os estudos estatísticos com amostras grandes predominam, alguns usaram variáveis incomuns ao campo, como proxy da capacidade estatal, a exemplo da data do primeiro Censo Nacional (Centeno, 2002), do uso do PIB per capita (Fearon e Laitin, 2003) ou de taxas de homicídio (Hamm; King, 2010). O nível de antiguidade da burocracia também é uma medida genérica que tem sido amplamente utilizada como proxy (Bockstette; Chanda; Putterman, 2002; Knutsen, 2013).

$\mathrm{Na}$ segunda abordagem, o foco dos estudos recai sobre apenas um aspecto da capacidade. Em alguns trabalhos, a dimensão de interesse corresponde às medidas claras (Evans e Rauch, 1999; Marenco; Strohschoen; Joner, 2017; Souza, 2016, 2017), enquanto em outros a partida é menos direta, como, por exemplo, Hendrix (2010) e Cárdenas (2010), que estudam a capacidade administrativa/burocrática utilizando como proxies a exportação de commodities e o índice de confisco e nacionalização forçada, respectivamente.

A terceira abordagem reconhece múltiplas dimensôes da capacidade estatal, levando a indicadores compostos ou agregados que contabilizam muitos aspectos diferentes, e é utilizada como estratégia para superar a natureza multidimensional do tema. Kocher (2010) recorre ao poder do exército (coerciva), ao profissionalismo burocrático (administrativa), aos impostos (fiscal), às redes rodoviárias (infraestruturais) e às restriçôes ao Executivo (legal) para conceituar a capacidade estatal. Fortin (2010) combina corrupção (administrativa), dinheiro retido nos bancos e direitos de propriedade (legal), imposto sobre receita (fiscal) e reformas infraestruturais (infraestrutural), criando um ranking das cinco medidas de capacidade estatal para os países pertencentes à Organizaçấo de Cooperaçấo e de Desenvolvimento Econômico (OECD).

De acordo com Cingolani (2013, p. 39):

A falta de boas estruturas conceituais pode criar problemas importantes. Por um lado, pode levar a contradiçốes bruscas (por exemplo, o poder do exército está diretamente ou inversamente relacionado com a capacidade do estado?). Por outro lado, pode levar ao uso de variáveis de resultados teoricamente opostas como medidas alternativas do mesmo conceito, mesmo que estejam positivamente associados ao mundo real.

Após a sistematização de estudos que se debruçaram sobre como estabelecer formas de medir a capacidade estatal, seja por meio da criação de abordagem analítica própria ou por outras desenvolvidas por estudiosos do campo, foi possível identificar algumas questôes. A maior parte da literatura se preocupou em associar a capacidade estatal à capacidade administrativa, utilizando como proxies as características weberianas, sofrendo influência de Evans e Rauch (1999). Para esses autores, a capacidade estatal envolveria, entáo, a habilidade de implementaçáo das políticas públicas, o que exigiria uma burocracia profissional dotada de recursos e de instrumentos necessários, conforme estabelecido por Gomide (2016). Entretanto, a maior parte as pesquisas desenvolvidas teve sob foco de análise apenas a burocracia, sem levar em consideração os recursos e instrumentos de que esta dispunha para desempenhar sua funcionalidade.

Algumas dimensóes da capacidade estatal ainda carecem de formas de mensuração. 
A principal delas, a política, foi analisada mais recentemente na literatura nacional por Gomide e Pires (2012), Pires e Gomide (2014, 2016), Marenco, Strohschoen e Joner (2017) e Nunes (2018). Destaca-se também a capacidade relacional, uma vez que a formulação e a implementação de políticas pública sofrem influência de vários atores, como, por exemplo, a sociedade, que tem papel preponderante, principalmente para as políticas de desenvolvimento (Evans, 1995). Por conseguinte, a concertação é fundamental para a efetividade da política. Outras são mais recorrentes na literatura nacional, como a capacidade de coordenação, cuja relevância pode estar associada às características do sistema federativo brasileiro.

\section{À guisa de conclusão}

Este trabalho objetivou sistematizar a literatura relativa à capacidade estatal, dando ênfase às definiçôes, às dimensões e às formas de mensurá-la. Foi possível constatar a expansão do campo de estudo OU constatar a expansão de pesquisas sobre a temática. Também nos aproximamos das bases teóricas e metodológicas mobilizadas e encontramos gaps na literatura, isto é, áreas ainda pouco pesquisadas, carentes de maior atenção acadêmica, sendo esta a relevância da revisão.

Em relação à variedade conceitual, constatamos que no debate internacional as definiçôes vão das mais simples até as mais complexas, contudo, elas convergem para o destaque da retomada da centralidade do Estado no exercício de suas atividades, a exemplo da promoção do desenvolvimento, da resolução de conflitos sociais etc. Isso estaria relacionado à existência de uma burocracia profissionalizada e insulada de interesses dos grupos sociais, assim como à mudança de padrão quanto à compreensão do papel desempenhado pela sociedade: de ator passivo a agente.

Quando discutimos o emprego do conceito na análise de políticas no Brasil, pôde-se perceber que os autores acionaram, principalmente, as capacidades de coordenação, administrativa, relacional e política, o que nos levou à necessidade de especificar tais dimensôes. No tocante às dimensôes da capacidade estatal, apesar de haver proposições diversas, muitas são convergentes, uma vez que expressam as mesmas dinâmicas. Percebeu-se também que alguns autores preferem manusear dimensóes mais amplas, que abarcariam as mais específicas.

Acerca das formas de medir as capacidades estatais, grande parte dos estudos se preocupou em associar a capacidade estatal à administrativa, utilizando, sob influência de Evans (1995), as características weberianas como proxies. Por conseguinte, a principal lacuna identificada foi a necessidade de expansão de estudos envolvendo os recursos e os instrumentos dos quais a burocracia dispóe para a implementaçáo de políticas públicas, visto que a profissionalização da burocracia já foi amplamente explorada. Outra lacuna consiste na escassez de estudos sobre a forma de medir as capacidades política e relacional. As capacidades administrativa, política e relacional foram utilizadas em modelos analíticos por Gomide e Pires (2012), Pires e Gomide (2014, 2016), Nunes (2018), todavia, ainda existe potencial de ampliaçáo de estudos envolvendo tais dimensôes. Por fim, entre nós, ganha atenção a dimensão da coordenação, tendo em vista o sistema federativo que coloca em jogo a autonomia e a interdependência dos entes nos processos das políticas públicas. 


\section{Bibliografia}

ACEMOGLU, D.; JOHNSON, S.; ROBINSON, J. A. The colonial origins of comparative development: An empirical investigation. American Economic Review, v. 91, n. 5, 1369-1401, 2001. http://doi.org/10.3386/w7771

ACEMOGLU, D.; TICCHI, D.; VINDIGNI, A. Emergence and persistence of inefficient states. Journal of the European Economic Association, v. 9, n. 2, p. 177-208, 2011. http://doi.org/10.3386/w12748

ACEMOGLU, D.; TICCHI, D.; VINDIGNI, A. Emergence and persistence of inefficient states. National Bureau of Economic Research Working Paper Series, n. 12748, 2006.

ANASTASIA, F.; LAS CASAS, L. Instituiçôes Políticas, Capacidades Estatais e Cooperação Internacional: África do Sul, Brasil e China. In: GOMIDE, A. A.; BOSCHI, R. R. (orgs.). Capacidades Estatais em Países Emergentes: o Brasil em perspectiva comparada. Rio de Janeiro: Instituto de Pesquisa Econômica Aplicada, 2016.

BÄCK, H.; HADENIUS, A. Democracy and State Capacity: Exploring a J-Shaped Relationship. Governance, v. 21, n. 1, p. 1-24, 2008. https://doi.org/10.1111/j.1468-0491.2007.00383.x

BAUNSGAARD, T.; KEEN, M. Tax revenue and (or?) trade liberalization. International Monetary Fund, 2005.

BAUNSGAARD, T.; KEEN, M. Tax revenue and (or?) trade liberalization. Journal of Public Economics, v. 94, n. 9-10, p. 563-577, 2010. https://doi.org/10.1016/j.jpubeco.2009.11.007

BERKMAN, H.; SCARTASCINI, C.; STEIN, E.; TOMMASI, M. Political institutions, state capabilities, and public policy: an international dataset. Washington, DC, United States: IDB Research Department, 2008.

BESLEY, T.; PERSSON, T. Pillars of Prosperity: The Political Economics of Development Clusters. Princeton: Princeton University Press, 2011.

BESLEY, T.; PERSSON, T. The origins of state capacity: Property rights, taxation, and politics. American Economic Review, v. 99, n. 4, p. 1218-1244, 2009. https://doi.org/10.3386/w13028

BESLEY, T.; PERSSON, T. The origins of state capacity: Property rights, taxation, and politics. National Bureau of Economic Research Working Paper Series, n. 13028, 2007.

BESLEY, T.; PERSSON, T. Wars and state capacity. Journal of the European Economic Association, v. 6, n. 2-3, p. 522-530, 2008. https://doi.org/10.1162/JEEA.2008.6.2-3.522

BICHIR, R. M. A Emergência e a Consolidação de Programas de Transferência de Renda no Brasil, na Argentina e na Africa do Sul. In: GOMIDE, A. A.; BOSCHI, R. R. (orgs.). Capacidades Estatais em Países Emergentes: o Brasil em perspectiva comparada. Rio de Janeiro: Instituto de Pesquisa Econômica Aplicada, 2016.

BOCKSTETTE, V.; CHANDA, A.; PUTTERMAN, L. States and Markets: The Advantage of an Early Start. Journal of Economic Growth, v. 7, n. 4, p. 347-369, 2002. https://doi.org/10.1023/A:1020827801137

BUHAUG, H. Dude, where's my conflict? LSG, relative strength, and the location of civil war. Conflict Management and Peace Science, v. 27, n. 2, p. 107-128, 2010. https://doi.org/10.1177\%2F0738894209343974

CÁRDENAS, M. State Capacity in Latin America. Global Economy and Development at Brookings Institution, p. 1-50, 2010.

CÁRDENAS, M.; ESLAVA, M.; RAMÍREZ, S. External Wars, Internal Conflict and State Capacity: Panel Data Evidence. Latin America Initiative at Brookings Institution, 2011.

CASTRO, A. C. Políticas de Inovação e Capacidades Estatais Comparadas: Brasil, China e Argentina. In: GOMIDE, A. A.; BOSCHI, R. R. (orgs.). Capacidades Estatais em Países Emergentes: o Brasil em perspectiva comparada. Rio de Janeiro: Instituto de Pesquisa Econômica Aplicada, 2016. 
CENTENO, M. A. Blood and Debt: War and The Nation-State in Latin America. Pensilvânia: Pennsylvania State University Press, 2002.

CHARRON, N.; LAPUENTE, V. Does democracy produce quality of government? European Journal of Political Research, v. 49, n. 4, p. 443-470, 2010. https://doi.org/10.1111/j.1475-6765.2009.01906.x

CINGOLANI, L. The State of State Capacity: a review of concepts, evidence and measures. Working paper, n. 31. Maastricht: Graduate School of Governance, 2013. 58 p.

CINGOLANI, L.; THOMSSON, K.; DE CROMBRUGGHE, D. Minding Weber more than ever? The impacts of state capacity and bureaucratic autonomy on development goals. World Development, v. 72, p. 191-207, 2013. https://dx.doi.org/10.2139/ssrn.2456595

DELGADO, I. G. Dilemas de Coordenaçâo e Capacidades do Estado para a Política Industrial: Trajetórias e Horizontes da China, da Índia e do Brasil. In: GOMIDE, A. A.; BOSCHI, R. R. (orgs.). Capacidades Estatais em Países Emergentes: o Brasil em perspectiva comparada. Rio de Janeiro, Instituto de Pesquisa Econômica Aplicada, 2016.

DEROUEN, K. et al. Civil war peace agreement implementation and state capacity. Journal of Peace Research, v. 47, n. 3, p. 333-346, 2010. https://doi.org/10.1177\%2F0022343310362169

DINCECCO, M. Political Transformations and Public Finances: Europe, 1650-1913. New York: Cambridge University Press, 2011.

DINCECCO, M.; KATZ, G. State capacity and long-run performance. The Economic Journal, v. 126, n. 590, p. 189-218, 2016. https://doi.org/10.1111/ecoj.12161

DINCECCO, M.; PRADO, M. Warfare, fiscal capacity, and performance. Journal of Economic Growth, v. 17, n. 3, p. 171-203, 2012. https://doi.org/10.1007/s10887-012-9079-4

DRAZEN, A.; ESLAVA, M. Electoral manipulation via voter-friendly spending: Theory and evidence. Journal of Development Economics, v. 92, n. 1, p. 39-52, 2010. https://doi.org/10.1016/j.jdeveco.2009.01.001

ESPING-ANDERSEN, G. As Três Economias Políticas do Welfare State. Lua Nova, n. 24, p. 85-116, 1991. http:// dx.doi.org/10.1590/S0102-64451991000200006

EVANS, P. Embedded Autonomy: States and Industrial Transformation. Nova Jersey: Princeton University Press, 1995.

EVANS, P. O Estado como problema e solução. Lua Nova, n. 28-29, p. 107-157, 1993. http://dx.doi.org/10.1590/ S0102-64451993000100006

EVANS, P.; RAUCH, J. Bureaucracy and Growth: A Cross-National Analysis of the Effects of "Weberian" State Structures on Economic Growth. American Sociological Review, v. 64, n. 5, p. 748-765, 1999. http://dx.doi. org/10.2307/2657374

EVANS, P.; RUESCHEMEYER, D.; SKOCPOL, T. Bringing the State Back in. Cambridge: Cambridge University Press, 1985.

FEARON, J. D.; LAITIN, D. D. Ethnicity, insurgency, and civil war. American Political Science Review, v. 97, n. 1, p. 75-90, 2003. https://doi.org/10.1017/S0003055403000534

FONSECA, I. F. da. Capacidades Estatais e Políticas Ambientais: Uma Análise Comparada dos Processos de Coordenação Intragovernamental para o Licenciamento Ambiental de Grandes Barragens (Brasil, China e Índia). In: GOMIDE, A. A.; BOSCHI, R. R. (orgs.). Capacidades Estatais em Países Emergentes: o Brasil em perspectiva comparada. Rio de Janeiro: Instituto de Pesquisa Econômica Aplicada, 2016.

FORTIN, J. A tool to evaluate state capacity in post-communist countries, 1989-2006. European Journal of Political Research, v. 49, n. 5, p. 654-686, 2010. https://doi.org/10.1111/j.1475-6765.2009.01911.x 
FUKUYAMA, F. State-building: governance and world order in the 21st century. New York: Cornell University Press, 2004.

FUKUYAMA, F. What is governance? Technical Report Working Paper 314, Center for Global Development, 2013.

GAITÁN, F.; BOSCHI, R. R. Estado, Atores Predominates e Coalizóes para o Desenvolvimento: Brasil e Argentina em Perspectiva Comparada. In: GOMIDE, A. A.; BOSCHI, R. R. (orgs.). Capacidades Estatais em Países Emergentes: o Brasil em perspectiva comparada. Rio de Janeiro: Instituto de Pesquisa Econômica Aplicada, 2016.

GATES, S.; HEGRE, H.; JONES, M. P.; STRAND, H. Institutional inconsistency and political instability: Polity duration, 1800-2000. American Journal of Political Science, v. 50, n. 4, p. 893-908, 2006. https://doi. org/10.1111/j.1540-5907.2006.00222.x

GEDDES, B. Politician's Dilemma: Building State Capacity in Latin America. Berkeley / Los Angeles: University of California Press, 1994.

GOMES, E. Relaçôes Estado-Sociedade e Novas Capacidades Estatais para o Desenvolvimento entre os Países do BRICS: O Brasil em Perspectiva Comparada com a África do Sul e a Índia. In: GOMIDE, A. A.; BOSCHI, R. R. (orgs.). Capacidades Estatais em Países Emergentes: o Brasil em perspectiva comparada. Rio de Janeiro: Instituto de Pesquisa Econômica Aplicada, 2016.

GOMIDE, A. de Á. Capacidades estatais para políticas públicas em países emergentes: (des)vantagens comparativas do Brasil. In: GOMIDE, A. A.; BOSCHI, R. R. (orgs.). Capacidades Estatais em Países Emergentes: o Brasil em perspectiva comparada. Rio de Janeiro: Instituto de Pesquisa Econômica Aplicada, 2016.

GOMIDE, A. de Á.; PIRES, R. R. C. Capacidades Estatais para o Desenvolvimento no Século XXI. Boletim de Análise Político-Institucional, p. 25-30, 2012.

GOODWIN, J. No other way out: states and revolutionary movements, 1945-1991. New York: Cambridge University Press, 2001.

GOYER, D. S.; DOMSCHKE, E.; DRAAIJER, G. E. The Handbook of National Population Censuses. Connecticut: Greenwood Press, 1983.

GRIN, E. J. et al. Sobre desconexōes e hiatos: uma análise de capacidades. Cadernos Gestáo Pública e Cidadania, São Paulo, v. 23, n. 76, p. 312-336, set./dez. 2018. http://dx.doi.org/10.12660/cgpc.v23n76.75417

HAMM, P.; KING, L. Post-Manichean Economics: Foreign Investment, State Capacity and Economic Development in Transition Economies. Working papers, n. 227. Amherst: Political Economy Research Institute, 2010.

HAMM, P.; KING, L. P.; STUCKLER, D. Mass privatization, state capacity, and economic growth in postcommunist countries. American Sociological Review, v. 77, n. 2, p. 295-324, 2012. https://doi. org/10.1177/0003122412441354

HANSON, J.; SIGMAN, R. Leviathan's Latent Dimensions: Measuring State Capacity for Comparative Political Research. In: AMERICAN POLITICAL SCIENCE ASSOCIATION 2011 MEETING. Anais [...]. Seattle: APSA, 2013.

HENDRIX, C. S. Measuring state capacity: Theoretical and empirical implications for the study of civil conflict. Journal of Peace Research, v. 47, n. 3, p. 273-285, 2010. https://doi.org/10.1177\%2F0022343310361838

HUMPHREYS, M. Natural resources, conflict, and conflict resolution uncovering the mechanisms. Journal of Conflict Resolution, v. 49, n. 4, p. 508-537, 2005. https://doi.org/10.1177/0022002705277545

HUNTINGTON, S. Political order in changing societies. New Haven: Yale University Press, 1968.

JAGUARIBE, A. Capacidades Estatais Comparadas: China e a Reforma do Sistema Nacional de Inovação. In: GOMIDE, A. A.; BOSCHI, R. R. (orgs.). Capacidades Estatais em Países Emergentes: o Brasil em perspectiva comparada. Rio de Janeiro: Instituto de Pesquisa Econômica Aplicada, 2016. 
JESSOP, B. Bringing the State Back In (Yet Again): Reviews, Revisions, Rejections, and Redirections. International Review of Sociology, v. 11, n. 2, p. 149-173, 2001.

JOHNSON, K.; RABINOWITZ, M. A. Relative political capacity model $\&$ data description. Paper prepared for the Workshop on Political Economy. Claremont Graduate University, 7 October, 2005.

KALYVAS, S. N. The logic of violence in civil war. New York: Cambridge University Press, 2006.

KING, R. G.; LEVINE, R. Finance and growth: schumpeter might be right. The Quarterly Journal of Economics, v. 108 , n. 3, p. $717-737,1993$. https://doi.org/10.2307/2118406

KNUTSEN, C. H. Democracy, State Capacity, and Economic Growth. World Development, v. 43, p. 1-18, 2013.

KOCHER, M. A. State Capacity as a Conceptual Variable. Yale Journal of International Affairs, v. 5, n. 2004, p. $137-145,2010$.

KUGLER, J.; ARBETMAN, M. Relative political capacity: political extraction and political reach. In: KUGLER, J.; ARBETMAN, M. (eds.). Political Capacity and Economic Behavior. Boulder, CO: Westview Press, 1997. p. 11-46.

LANZARA, A. P. Capacidades Estatais, Trabalho e Seguridade Social: África do Sul, Argentina e Brasil em Perspectiva Comparada. In: GOMIDE, A. A.; BOSCHI, R. R. (orgs.). Capacidades Estatais em Países Emergentes: o Brasil em perspectiva comparada. Rio de Janeiro: Instituto de Pesquisa Econômica Aplicada, 2016.

LEOPOLDI, M. A. Políticas de Internacionalização em Face dos Desafios do Século XXI: Instituiçôes e Políticas Voltadas para a Ampliação do Comércio Exterior e o Apoio às Multinacionais Brasileiras. In: GOMIDE, A. A.; BOSCHI, R. R. (orgs.). Capacidades Estatais em Países Emergentes: o Brasil em perspectiva comparada. Rio de Janeiro: Instituto de Pesquisa Econômica Aplicada, 2016.

LEVI, M. Of Rule and Revenue. Berkeley e Los Angeles: University of California Press, 1988.

MANN, M. The Sources of Social Power: A history of power from the beginning to A.D. 1760. New York: Cambridge University Press, 1986.

MANN, M. The Sources of Social Power. The rise of classes and nation-states, 1760-1914. New York: Cambridge University Press, 1993.

MARENCO, A.; STROHSCHOEN, M. T. B.; JONER, W. Capacidade estatal, burocracia e tributação nos municípios brasileiros. Revista de Sociologia e Política, v. 25, n. 64, p. 3-21, 2017. http://dx.doi.org/10.1590/1678987317256401

MCBRIDE, M.; MILANTE, G.; SKAPERDAS, S. Peace and war with endogenous state capacity. Journal of Conflict Resolution, v. 55, n. 3, p. 446-468, 2011. https://doi.org/10.1177\%2F0022002711400862

MIDGAL, J. S. Strong Societies and Weak States: State Society Relations and State Capabilities in the-Third-World. Princeton: Princeton University Press, 1988.

MITCHELL, B. International historical Statistics: the Americas. Detroit: Gale Research, 1983.

NUNES, W. Uma estratégia desenvolvimentista sem um Estado Desenvolvimentista: o caso dos governos Lula. In: ENCONTRO NACIONAL DA ABCP, 11., 2018. Anais [...]. Curitiba: ABCP, 2018.

PIRES, R.; GOMIDE, A. Capacidades estatais e democracia: arranjos institucionais de políticas públicas. Brasília: IPEA, 2014.

PIRES, R. R. C.; GOMIDE, A. de Á. Governança e capacidades estatais: uma análise comparativa de programas. Revista de Sociologia e Política, v. 24, n. 58, p. 121-143, 2016. http://dx.doi.org/10.1590/1678-987316245806 
RUESCHEMEYER, D.; EVANS, P. The state and economic transformation: Toward an analysis of the conditions underlying effective intervention. In: EVANS, P. B.; RUESCHEMAYER, D.; SKOCPOL, T. (eds.). Bringing the State Back in. Cambridge: Cambridge University Press, 1985.

ROBINSON, M. Hybrid states: Globalisation and the politics of state capacity. Political Studies, v. 56, n. 3, p. 566583, 2008. https://doi.org/10.1111\%2Fj.1467-9248.2008.00751.x

SANTANA, C. H. V. Política de Infraestrutura Energética e Capacidades Estatais nos BRICS. In: GOMIDE, A. A.; BOSCHI, R. R. (orgs.). Capacidades Estatais em Países Emergentes: o Brasil em perspectiva comparada. Rio de Janeiro: Instituto de Pesquisa Econômica Aplicada, 2016.

SKOCPOL, T. Bring the State Back In: Strategies of Analysis in Current Research. In: EVANS, P.; RUESCHEMEYER, D.; SKOCPOL, T. (orgs.). Bringing the State Back in. Cambridge: Cambridge University Press, 1985.

SKOCPOL, T. States and Social Revolutions: a Comparative Analysis of France, Russia and China. New York: Cambridge University Press, 1979.

SOIFER, H. D. Authority over distance: explaining variation in state infrastructural power in Latin America. California: Harvard University, 2006.

SOIFER, H. State infrastructural power: Approaches to conceptualization and measurement. Studies in Comparative International Development, v. 43, n. 3-4, p. 231-251, 2008. https://doi.org/10.1007/s12116-008-9028-6

SOUZA, C. Capacidade Burocrática no Brasil e na Argentina: Quando a Política faz a Diferença. In: GOMIDE, A. A.; BOSCHI, R. R. (orgs.). Capacidades Estatais em Países Emergentes: o Brasil em perspectiva comparada. Rio de Janeiro: Instituto de Pesquisa Econômica Aplicada, 2016.

SOUZA, C. Capacidade Burocrática no Brasil e na Argentina: Quando a Política faz a Diferença. Rio de Janeiro: IPEA, 2015. (Texto para Discussão, n. 2.035.)

SOUZA, C. Modernização do Estado e construção de capacidade burocrática para a implementação de políticas federalizadas. Revista de Administraçáo Pública, v. 51, n. 1, p. 27-45, 2017. http://dx.doi.org/10.1590/0034-7612150933

STEFFEN, M. W. Bancos Multilaterais de Desenvolvimento como Atores de Política Social: O Caso do Banco Mundial na América Latina e Caribe (2008 - 2014). Dissertaçáo (Mestrado em Política Públicas) Universidade Federal do Rio Grande do Sul, Porto Alegre, 2017.

STRAUS, S. The order of genocide: race, power, and war in Rwanda. New York: Cornell University Press, 2006. 273 p.

THIES, C. G. Of rulers, rebels, and revenue: State capacity, civil war onset, and primary commodities. Journal of Peace Research, v. 47, n. 3, p. 321-332, 2010. https://doi.org/10.1177\%2F0022343310361841

TILLY, C. The Formation of National States in Western Europe. Princeton: Princeton University Press, 1975.

VAUGHAN, M. K. Cultural politics in revolution: teachers, peasants, and schools in Mexico, 1930-1940. Tucson: University of Arizona Press, 1997.

WEBER, E. Peasants into Frenchmen: the modernization of rural France, 1870-1914. California: Stanford University Press, 1976.

WEAVER, R. K.; ROCKMAN, B. A. Do institutions matter?: government capabilities in the United States and abroad. Washington, D. C.: Brookings Institution Press, 1993.

WEISS, L. The Myth of the Powerless State: Governing the Economy in a Global Era. New York: Cornell University Press, 1998.

WORLD BANK. World development report 1997: the state in a changing world. Washington, D. C.: World Bank Group, 1997. 


\section{Resumo}

\section{Capacidade estatal: definiçōes, dimensóes e mensuraçâo}

No campo das políticas públicas, o debate em torno das capacidades estatais ganhou centralidade nas últimas décadas. Isso porque se passou a relacioná-las à eficiência e à efetividade da ação estatal. Nessa ideia, as capacidades estatais seriam causa e resultado de políticas públicas melhores. Na esteira dessa relevância, este artigo discorre sobre as definiçôes, dimensôes e formas de mensuraçáo dessas capacidades. Para tanto, são apresentadas e discutidas as principais contribuiçóes das produçóes nacional e internacional. Dessa maneira, contribui-se para a literatura ao sistematizar os diversos entendimentos de um conceito que vem sendo apropriado tanto na análise de políticas públicas quanto na administração pública.

Palavras-chave: Capacidade estatal; Políticas públicas; Administração pública; Burocracia; Coordenação.

\section{Abstract}

\section{State capacity: definitions, dimensions and measure}

In the field of public policies, the debate over state capacities has gained centrality in the last decades. This is mostly due to recent relations to the efficiency and effectiveness of state action. In this sense, state capacities both cause and result from better public policies. Based on these considerations, this paper puts forward definitions, dimensions and measures of these capacities, presenting and discussing main contributions of national and international productions. Thus, we contribute to the public policy literature by systematizing various understandings of a concept that has been adopted in the analysis of both public policies and public administration.

Keywords: State capacity; Public policies; Public administration; Bureaucracy; Coordination.

\section{Résumé}

\section{Capacite de l'état: definitions, dimensions et mesure}

Dans le domaine des politiques publiques, le débat sur les capacités de l'État a pris une place centrale au cours des dernières décennies. Cela est principalement dû aux relations récentes avec l'efficience et l'efficacité de l'action de l'État. En ce sens, les capacités des États sont à la fois la cause et le résultat de meilleures politiques publiques. Sur la base de ces considérations, le présent document propose des définitions, des dimensions et des mesures de ces capacités, et présente et discute les principales contributions des productions nationales et internationales. Ainsi, nous contribuons à la littérature sur les politiques publiques en systématisant diverses interprétations d'un concept qui a été adopté dans l'analyse des politiques publiques et de l'administration publique.

Mots-clés: Capacité de l'état; Politiques publiques; Administration publique; Bureaucratie; Coordination. 